\title{
MAGMATISMO PÓS-PALEOZÓICO NO NORDESTE ORIENTAL DO BRASIL
}

\author{
FERNANDO FLÁ VIO MARQUES DE ALMEIDA*, CELSO DAL RÉ CARNEIRO*, \\ DELZIO DE LIMA MACHADO Jr.* e LAURO KAZUMI DEHIRA**
}

\begin{abstract}
POST-PALAEOZOIC MAGMATISM OF THE EASTERN PART OF THE NORTHEASTERN BRAZIL. Since the Jurassic, the area of Northeastern Brazil was affected by several magmatic events, both intrusive and effusive ones. The ages of the igneous bodies are not perfectly known, but it can be stated that some sedimentary basins accomodated prominent part of the geologic record from the igneous activity. The area north to the $8^{\circ} \mathrm{S}$ parallel was more intenselly affected, comprising deposits in the Parnaíba, Potiguar, and Lavras da Mangabeira basins. The occurrences are relatively scattered on Precambrian areas, restricted to zones very far from the São Francisco Cráton. There are three main age groups. The Juro-Cretaceous bodies (pre-Aptian) are composed of tholeiitic basalts normally without olivine. The Albian and Tertiary ones usually exhibit modal olivine and alkaline composition. It seems that a quiet phase occurred comprising the Neocretaceous and the Paleocen. Based on aeromagnetic and geologic maps at a regional scale, it has been possible to show that some areas were strongly attected by 1gneous activity. Part of them can be followed along hundreds of kilometers, in a shape of igneous allignements. The most expressive are the Rio Ceará-Mirim, the Mecejana-Fernando de Noronha, both trending E-W, and Macau-Queimadas, trending NNW. The former is related to Neocomian, and the others belong to the Tertiary. There are no Quaternary igneous activity in the continental area, but some oceanic islands were evolved until the end of the tertiary.
\end{abstract}

RESUMO A partir do Jurássico, o Nordeste do Brasil sofreu diversos eventos magmáticos, intrusivos e efusivos, cujas idades são ainda mal conhecidas. Seus registros são mais bem definidos acima do paralelo de $8^{\circ} \mathrm{S}$, concentrando-se em algumas bacias sedimentares, como as do Parnaíba, Potiguar e Lavras da Mangabeira. Nas áreas pré-cambrianas, as ocorrências são relativamente dispersas, restringindo-se a porções afastadas do Cráton do São Francisco. O presente trabalho constitui uma síntese de conhecimentos que integra os dados da literatura e dos mapas disponíveis sobre essa atividade ígnea mesozóico-cenozóica no Nordeste Oriental. Por meio de uma comparação das informaçoes coletadas com a expressão geofísica dos registros, novas ocorrências de corpos ígneos são detectadas e seu significado é discutido. O estudo procura contribuir para se conhecer melhor os estágios da Ativação Mesoź́ica na região. Três grupos principais de idade sâo conhecidos. Nas manifestações juro-cretáceas (pré-aptianas) predominam basaltos toléticos, geralmente nảo-olivínicos, enquanto os albianos e terciários geralmente apresentam olivina modal e composição alcalina. Aparentemente, houve uma fase de quietude compreendendo o Neocretáceo e o Paleoceno. Enfatiza-se a existência de dois alinhamentos de corpos ígneos: os diques do Magmatismo Rio Ceará-Mirim (J-K), dispostos segundo E-W, e os corpos intrusivos e extrusivos vinculados à Formação Macau (Eoceno-Mioceno), que se alinham segundo uma zona N-S a NNW, afastada cerca de $150 \mathrm{~km}$ da regiảo costeira entre Natal e Recife.

\section{INTRODUÇÃO}

Acompanhando a evolução tectônica do Nordeste Oriental a partir do Jurássico, manifestaram-se fenômenos magmáticos intrusivos e efusivos que deram origem a variados tipos litológicos. Os mais antigos são preponderantemente basaltos tolé́ticos geralmente não-olivínicos enquanto os albianos e terciários derivam de magma olivina basálticos alcalino. A julgar pelas ainda pouco numerosas dataçőes isotópicas, as rochas alcalinas terciárias foram precedidas de longo hiato compreendendo todo o Neocretáceo.

Almeída (1986) apresentou uma síntese de conhecimentos acerca do magmatismo pós-paleozóico no Brasil, na qual descreveu sucintamente os registros de eventos ígneos no Nordeste Oriental. O presente trabalho constitui um detalhamento daquele estudo a partir de dados coligidos da literatura. Abrange a área a norte do paralelo $13^{\circ} \mathrm{S}$ e a leste do meridiano $42^{\circ} \mathrm{WG}$, indicada na figura 1 . A análise de mapas aerogeofísicos de vários projetos que recobrem o Nordeste Oriental (Carneiro et al. 1988) permitiu acrescentar novas evidências sobre a distribuição de corpos magmáticos no Nordeste brasileiro.

MATERIAIS E MÉTODOS O trabalho, essencialmente de revisão bibliográfica, foi acompanhado de uma análise de cartas aeromagnéticas e geológicas com o intuito de conhecer mais precisamente a distribuição da atividade ígnea. Foram consultadas as publicações disponíveis na literatura especializada bem como numerosos relatórios e mapas inéditos focalizando a área estudada (Fig. 1). Esses documentos foram obtidos com a colaboração de orgãos como a Petrobrás, DNPM, Nuclebrás e Universidade Federal de Ouro Preto.

$\mathrm{Na}$ análise de mapas aerogeofísicos, foi empregada a técnica de comparação entre cartas aeromagnéticas (de escala variável entre 1:50.000 e 1:250.000) com os mapas geológicos correspondentes. Foram consultados diversos mapas, listados no IPT (1988), entre os quais se destacam os do Projeto Radambrasil ao milionésimo (Radambrasil várias datas) e do Projeto "Mapas Metalogenéticos e de Previsão de Recursos Minerais" (DNPM/CPRM várias datas) estes na escala 1:250.000.

Como fruto da compilação de dados sobre registros de campo de corpos ígneos mesozóico-cenozóicos foi elaborado um mapa geológico na escala 1:2.500.000 (IPT 1988), no qual foram discriminadas as ocorrências conhecidas de corpos ígneos de idade mesoz6ico-cenozóica no Nordeste Oriental e plataforma continental adjacente. Algumas das ilustrações aqui contidas reproduzem trechos daquele mapa.

\section{A IDADE DO MAGMATISMO E SUA DISTRI-} BUIÇÃO Na região considerada não se reconheceram até agora evidências de magmatismo permo-triássico, como existem a oeste da Bacia do Parnaíba e na região Amazônica.

* Instituto de Pesquisas Tecnológicas do Estado de São Paulo (IPT), Divisão de Minas e Geologia Aplicada. Cidade Universitária, Caixa Postal 7141, CEP 05508, São Paulo, SP, e Instituto de Geociências da Universidade Estadual de Campinas (Unicamp)

** Instituto de Pesquisas Tecnologicas do Estado de São Paulo (IPT), Divisão de Minas e Geologia Aplicada 


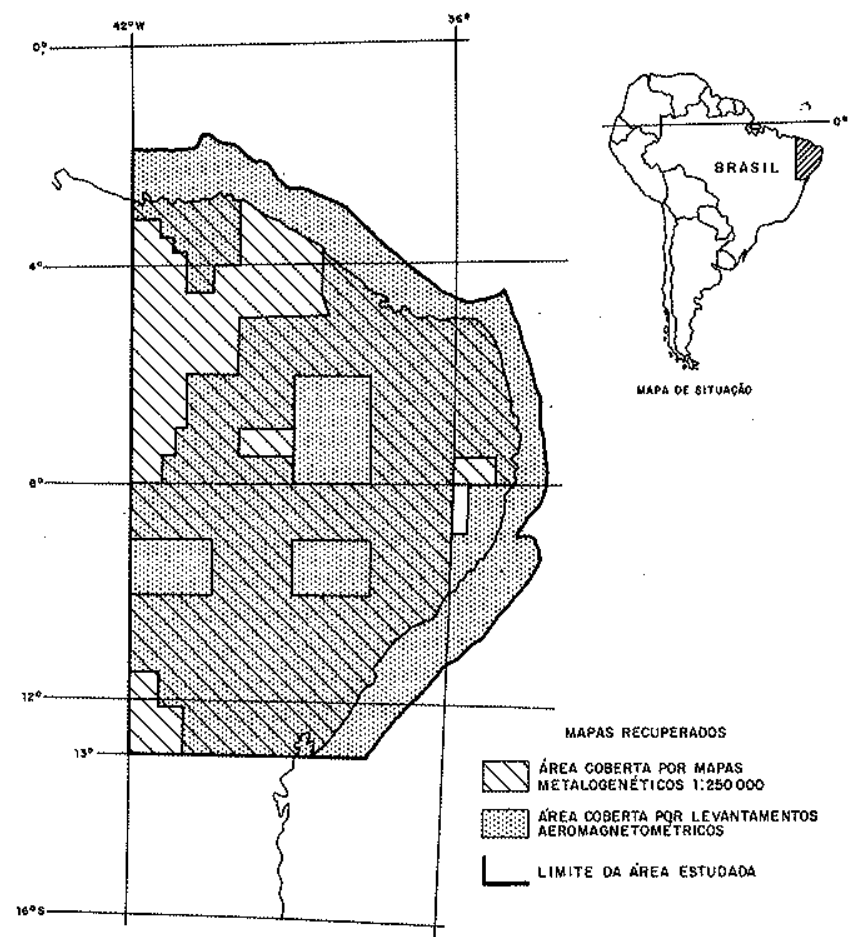

Figura 1 -Area de estudo e base cartográfica utilizada

Entre o Mesojurássico e o Eocretáceo pré-Aptiano manifestou-se magmatismo toleítico. Esse magmatismo ef representado na regiáo tão-somente por rochas intrusivas, tendo provavelmente sido erodidos os termos efusivos que persistem localmente junto ao Alto de Touros, na borda da Bacia Potiguar. A fase inicial perdurou, tanto quanto o indicam as informaçöes disponíveis, até o Barremiano, há cerca de $118 \mathrm{Ma}$. As rochas ígneas dessa longa fase magmática apresentam distribuição generalizada, fora do Cráton do São Francisco. No trecho oriental da Bacia do Parnaíba constituem diques e soleiras da chamada Formação Sardinha. $\mathrm{Na}$ area do embasamento cristalino tem como tipo os diques do Magmatismo Rio Ceará-Mirim, no Rio Grande do Norte e Ceará. Fazem parte desse conjunto, possivelmente, as rochas intrusivas nas camadas da Bacia de Lavras da Mangabeira.

Após um intervalo de tempo razoavel, apresentou-se, proximo à passagem do Albiano para o Cenomaniano, nova fase magmática de caráter alcalino e tendência álcali-cálcica com enriquecimento em sílica, constituindo a Formação Ipojuca, da costa de Pernambuco a sul do Recife. Embora as informações sejam muito escassas, é possível que a nova fase pertençam o Gabro de Curaçá (com idade cenomaniana determinada por Cordani 1970). na Bahia, e a Formaçăo Itapororoca na Paraíba.

A atividade fgnea terciária se apresentou entre o Paleogeno e o início do Neogeno (Mioceno). Caracterizou-se por sua natureza alcalina, em grande parte subsaturada. Compreende as formações Mecejana, no Ceara, e Macau, no Rio Grande do Norte e Parafba. Sua distribuiçăo é bem mais restrita que o magmatismo juromeocretáceo, pois seus locais de ocorrência se acham compreendidos no interior de uma faixa com cerca de $150 \mathrm{~km}$ de largura, a partir da borda do continente, e nas bacias Potiguar e Ceará (vulcanismos Mundaú, do Alto Atântico e do Alto do Ceara), situadas na margem continental. Ao contrário da atividade pré-aptiana, esse magmatismo se desenvolveu claramente em função da tectónica costeira da margem continental face à crosta oceânica.

Comparado com o magmatismo pós-paleozóico do Brasil Meridional, $o$ do Nordeste apresenta semelhanças e diversidades. $\mathrm{O}$ magmatismo jurássico-eocretáceo em ambas as regiôes pertence ao mesmo episódio que se manifestou na maior parte do país. Faltam no Nordeste Oriental, entretanto, complexos alcalinos e alcalino-ultramáficos, carbonatitos e kimberlitos, semelhantes aos que ocorrem às bordas da Bacia do Paraná. A longa fase neocretácea de relativa quietaçáo magmática no Nordeste coincide com uma importante época de intrusöes alcalinas no Brasil Meridional, expostas em arqueamentos, flexuras e zonas de rifle (Almeida 1983).

Em grande parte, o magmatismo tolé́tico coincidiu, no tempo, com o máximo de intensidade do tectonismo de falhas geradoras de bacias sedimentares da fase rifte, no interior do continente e na margem continental. Já os fenômenos vulcânicos do Terciário se relacionam ao estágio oceânico de separação dos blocos continentais e geração de assoalho oceânico. Eles não têm similar no restante do país, onde só em poucos locais, do Sudeste e Centro -Oeste, diques de rochas alcalinas têm sido datados do Eoceno. Na Bacia de Volta Redonda (RJ) há derrame dessa idade (Riccomini et al. 1983), parecendo ser contemporâneo ao vulcanismo havido na Depressão da Guanabara (Rodrigues et al. 1982, Klein \& Valença 1984). Todas essas ocorrências representam manifestaçōes tardias do importante magmatismo alcalino neocretáceo, mas não é este o caso do vulcanismo terciário do Nordeste do Brasil. É de se notar o caráter predominantemente alcalino a olivina basáltico das atividades magmáticas terciárias na Plataforma Sul-Americana.

O mapa da figura 2 sintetiza as denominaçóes para os diferentes registros de atividade ígnea pós-paleozóica na regiāo Nordeste Oriental do Brasil. Onde pertinente, as idades absolutas admitidas neste trabalho são discutidas em cada uma das descriçōes do registro ígneo.

Formação Sardinha $\mathrm{Na}$ borda oriental da Bacia do Parnaíba, a leste do meridiano $42^{\circ} \mathrm{WG}$, ocorrem soleiras e diques de diabásico tolético intrometidos nas camadas paleozóicas. Representam exposiçōes orientais de volumosas intrusōes que se mostram nas regiöes interiores da bacia, onde as soleiras alcançam espessuras totais próximas de $500 \mathrm{~m}$ (Fig. 3). As espessuras na borda leste da bacia, contudo, năo ultrapassam uma centena de metros.

Aguiar (1969) distinguiu entre os basaltos e diabásios da Bacia do Parnalba duas unidades de idades diversas. Os mais antigos incluem os derrames das regióes central e ocidental da bacia e sua idade radiometricamente confirmada corresponde ao intervalo do Neotriássico ao Jurássico (Lima \& Leite 1978). Não parecem ocorrer derrames à borda leste da bacia, onde todas as intrusões máficas nas camadas siluro-devono-mississipianas são atribuídas à Formação Sardinha, de Aguiar (op. cit.), assim tendo sido representadas no Mapa Geológico do Brasil em sua edição de 1981 (Schobbenhaus et al.1981), atribuindo-se-lhes idade cretácea.

A julgar por dataçőes disponíveis do Piaú (apud Sial 1976a) e por uma dataçâo de $171 \pm 8 \mathrm{Ma}$ de amostras procedentes do local Caldeirão, município de Cocal, no norte do Piauí (Nascimento et al. 1981), o magmatismo baśltico na regiấo leste da bacia também se realizou entre o Mesojurássico e o Eocretáceo pré-Aptiano, sendo assim coevo do Magmatismo Rio Ceará-Mirim.

Os diques de diabásio da Bacia do Parnaíba adotam duas direçōes preferenciais: N50-70E e N20-40W (Rezende 1964). A leste do meridiano $42^{\circ}$ WG os diques parecem escassos, mas seguem de preferência essas direçōes, o que também se observa nos que atravessam o embasamento cristalino logo a leste da bacia.

Magmatismo Rio Ceará-Mirim A denominação foi aplicada pelos ge6logos do Projeto Radambrasil (Gomes et al. 1981) para o magmatismo máfico tolético do conjunto de diques de diabásio (Fig, 4) que definem o "Alinhamento do Cabugi", proposto por Santos (1968). A denominaçăo Rio 


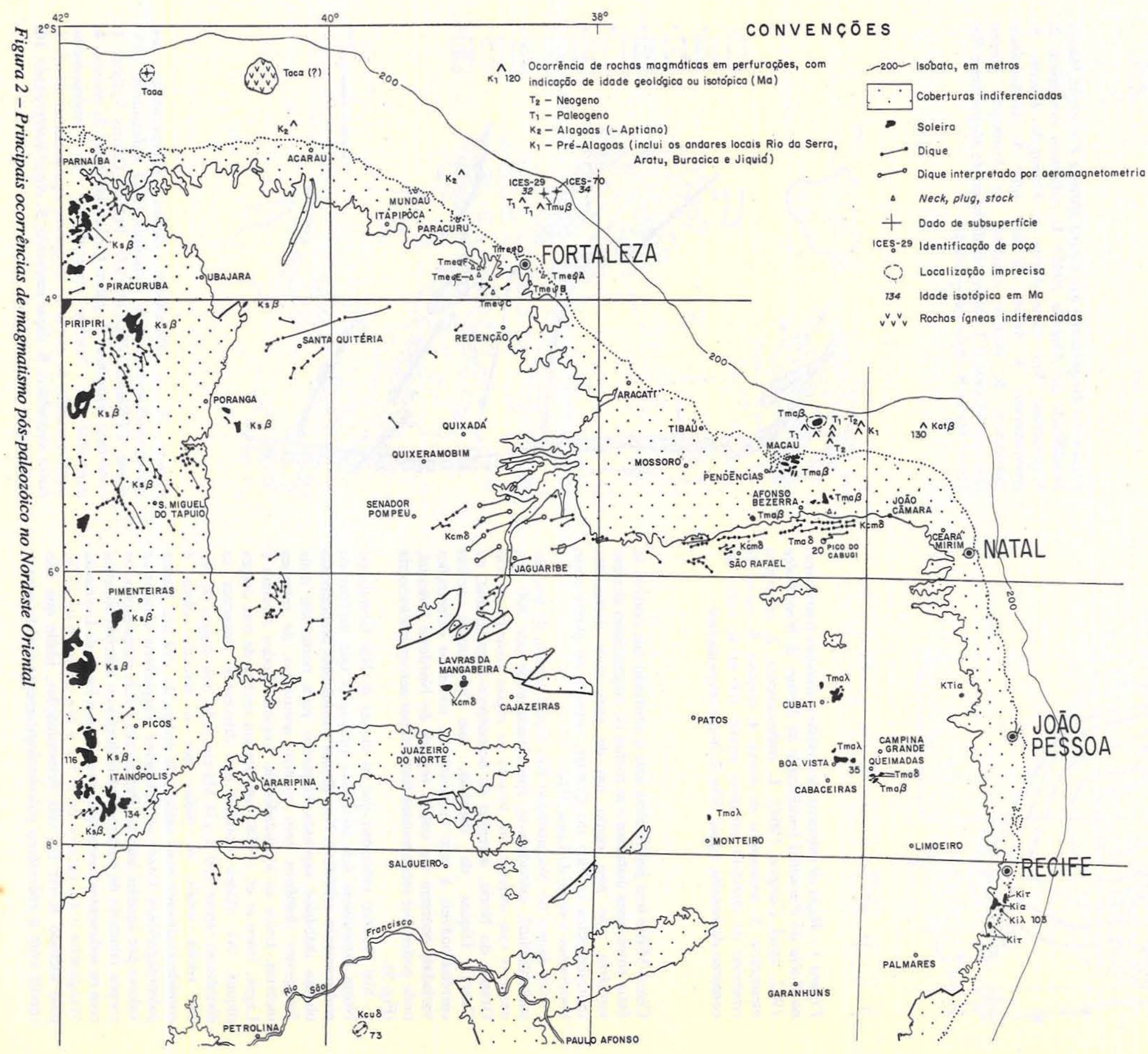

LEGENDA

TERCIÁRIO

VULCANISMO DO ALTO ATLÂNTICO

Tooa - riólito

VULCANISMO DO ALTO DO CEARÁ

Toca - riblito, gronito, rocha piroclóstico

FORMAÇÃO MACAU

Tmad - bosolto alcalin

Tmo $\beta$ - basolto, olivina - basolto

VULCANISMO MUNDAÚ

Tmu $\beta$ - rochos bósicas

VULCANISMO MECEJANA (OLIGOCENO)

\section{Tmega - Serrote Coruru}

Tmey B - Serrote Ancuri

Alcalinas Tha - Serrote Pao-ded

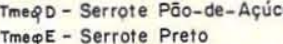

TmegF - Serrote Salgadinho

\section{NEOCRETÁCEO-TERCIÁRIO}

VULCANISMO ITAPOROROCA

KTia - Rocho efusivo decido

\section{CRETÁCEO}

GABRO DE CURAḈ (BA)

$$
\text { Keu8 - gobro }
$$

FORMAÇÃO IPOJUCA ( $K$ inf. - $K$ sup.)

Kia -rí́lito

Kiג - alcoligronito do Cabo de Santo Agostinho

\section{CRETÁCEO INFERIOR}

MAGMATISMO RIO CEARÁ-MIRIM

$$
\text { Kem8 - diabósio }
$$

VULCANISMO DO ALTO DE TOUROS

$$
\text { Kot } \beta \text { - bosolto }
$$

FORMAÇĀO SAROINHA

$\kappa_{s} \beta$ - diabósio, bosclto 

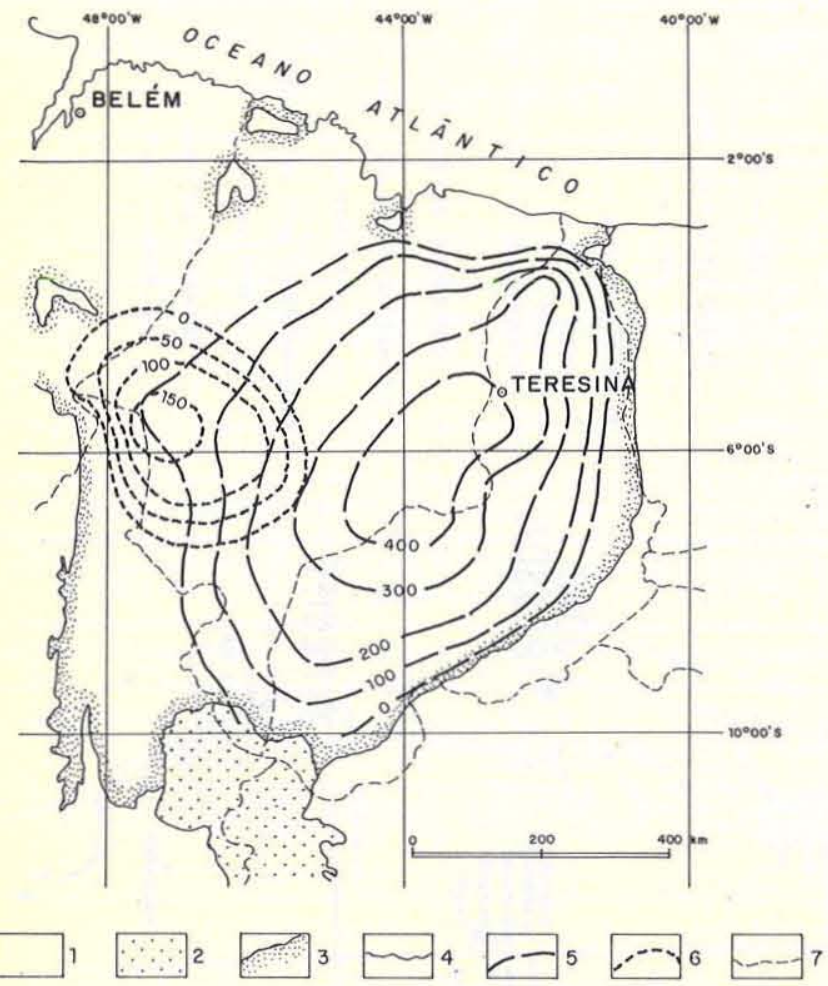

Figura 3-Mapa de isópacas de basalto e diabásio (intrusivos) na Bacia do Parnaíba (modificado de Mesne, \& Wooldridge 1962, apud Campos 1964): 1. embasamento; 2. cobertura mesozóica; 3. sedimentos da bacia; 4. contato; 5. curva de contorno de diabásio intrusivo, equid. $100 \mathrm{~m}$; 6. curva de contorno de basalto, equid. $50 \mathrm{~m}$; 7. limite interestadual

Ceará-Mirim tem justificativa ante a confusão que outrora se fazia entre esses diabásios e as rochas do magmatismo alcalino terciário, que tem como um de seus mais destacados representantes o Pico do Cabugi, situado no alinhamento homônimo, a oeste de Lajes (RN).

Os diques do Magmatismo Rio Ceará-Mirim, de traçado sublatitudinal, estendem-se aproximadamente por $300 \mathrm{~km}$, desde o vale daquele rio, situado na região costeira do Rio Grande do Norte, à regiâo de Solonópole-Jaguaretama, no Ceará. Diques de diabásio, que se supõe serem correlacionáveis a esse magmatismo, adotando orientações variadas, ocorrem em outras regiões do Nordeste Oriental, onde podem ser reconhecidos também por aeromagnetometria (Fig. 5).

Sial (1976a) menciona que os diques do Rio Grande do Norte constituem seis subfeixes principais que surgem do embasamento cristalino. Nos diques meridionais predominam olivina diabásios espessos enquanto para norte são mais freqüentes diabásios com quartzo normativo, de relaçōes incertas. Entre as localidades de Angicos, Pedro Avelino e Lages, Horn et al. (1988) amostraram rochas de très desses diques. As idades obtidas em diferentes materiais se distribuem entre 130 e $134 \mathrm{Ma}$ em dois dos diques (K-Ar em rocha total), ao passo que $o$ terceiro dique é consideravelmente mais antigo, da ordem de $150 \mathrm{Ma}$. Dados paleomagnéticos foram considerados compatíveis com esses valores por aqueles autores. Pertencem a esse magmatismo os corpos tabulares de basalto, concordantes ou subconcordantes com os sedimentos basais que preenchem a Bacia de Lavras da Mangabeira (CE), datados de $175 \pm 4$ Ma (Priem et al. 1978) pelo método $\mathrm{K}-\mathrm{Ar}$ em seis determinações, idade que não condiz com a eocretácea paleontologicamente obtida para o

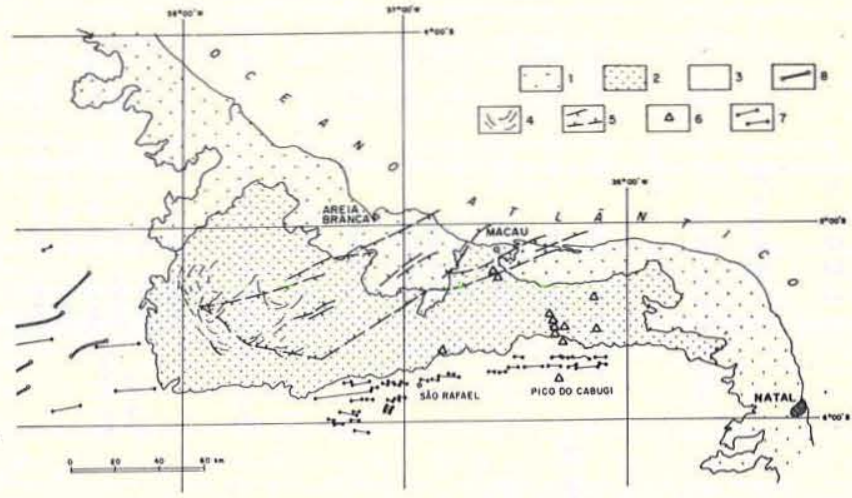

Figura 4 - Magmatismo Rio Ceará-Mirim e Formação Macau (modificado de Almeida 1986): 1. cobertura cenozóica; 2. Magmatismo Rio Ceará-Mirim e Formação Macau; 3. embasamento; 4. falhas da fase rifte; 5. alinhamentos estruturais; 6. rochas alcalinas da Formação Macau (Eoceno-Mioceno); 7. diques de diabásio do Magmatismo Rio Ceará-Mirim; 8. dique interpretado

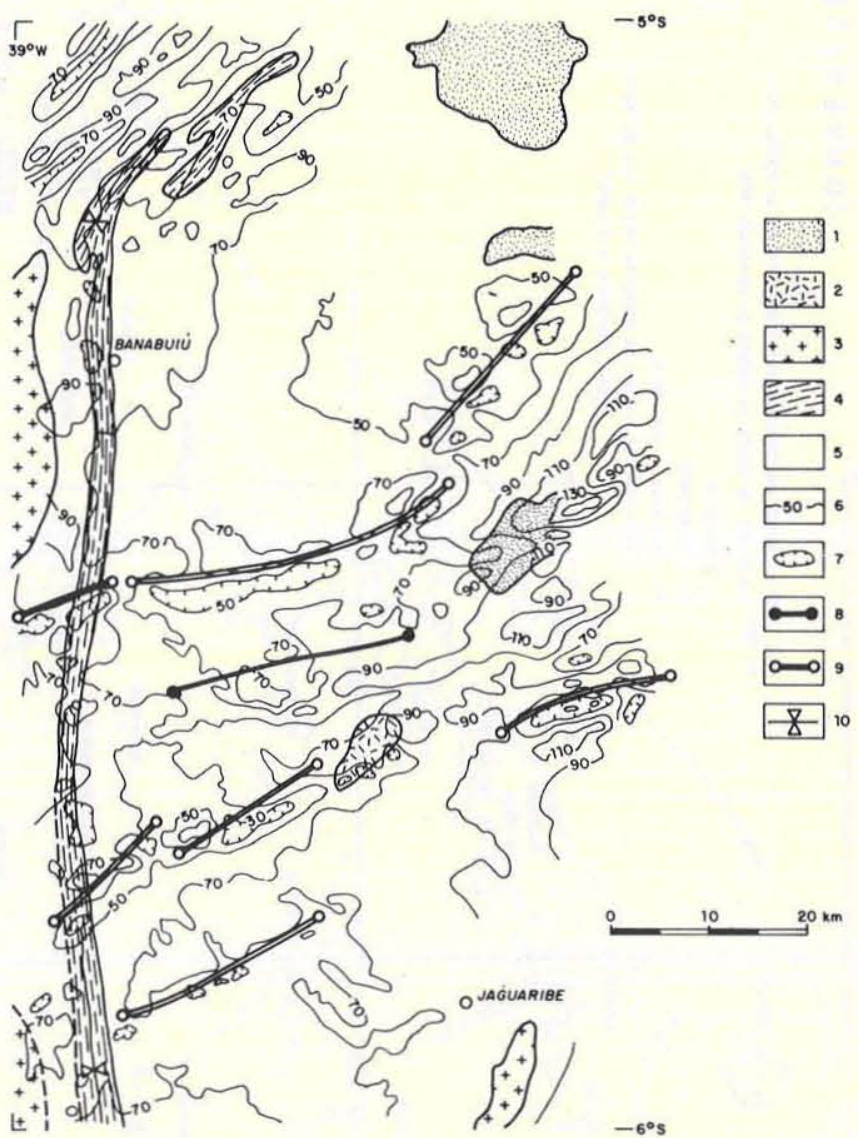

Figura 5 - Principais diques interpretados por aeromagnetometria entre Banabuiú (CE) e Jaguaribe (RN) (fonte: CPRM/GEOFOTO 1977, Projeto Cariris Velhos): 1. cobertura cenozóica; 2. gabro (pré-cambriano); 3. granito; 4. quartzitos $e$ rochas miloniticas; 5 . embasamento indiferenciado; 6. curva de isogamas, equidistância 20 nT; 7. baixo magnético; 8. dique mapeado; 9 . dique interpretado; 10. sinforma 
Grupo Rio do Peixe (Braun 1969), ao qual tais sedimentos são relacionados. Já Gomes et al. (op. cit.) citam esses diques como do Terciário Inferior, correlacionados portanto à Formação Macau da Bacia Potiguar. Possivelmente também ao Magmatismo Rio Ceará-Mirim pertencem os diques de diabásio próximos a Santa Quitéria (CE), um dos quais, orientado a ENE, é longo de $60 \mathrm{~km}$ e espesso de 30 a $800 \mathrm{~m}$ (Gomes et al. op. cit.). Braga et al. (1981) descreveram esses diques, que atribuiram ao magmatismo fissural máfico terciário (?) do Rio Grande do Norte.

A expressão aeromagnética dos diques é notável em mapas, seja pela linearidade e extensão das anomalias, seja pela posição destas, que se acham sempre muito próximas aos diques correspondentes. $\mathrm{Na}$ figura 5 tem-se uma interpretação aeromagnética na região do Vale do Rio Jaguaribe, a partir do Projeto Cariris Velhos (CPRM 1977). Foram identificadas diversas anomalias linearmente orientadas segundo E-W a ENE. São todas de baixa amplitude e pequeno comprimento de onda, sistematicamente com os baixos magnéticos dispostos na parte meridional. Tais anomalias foram relacionadas ao Magmatismo Rio Ceará-Mirim com base na presença de alguns diques conhecidos na área.

Dezenove datações $\mathrm{K}-\mathrm{Ar}$ referentes ao magmatismo basáltico jurássico-eocretáceo do Nordeste Oriental, obtidas por diversos autores desde os trabalhos iniciais de Ebert \& Brochini (1968), acham-se relacionados por Gomes et al. (op. cit.). Com exceção de duas idades consideradas anômalas, todas indicam valores entre 175 e $118 \mathrm{Ma}$, correspondentes ao Mesojurássico (Bajociano) e Eocretáceo pré-Aptiano. Não se dispõe de número suficiente de dataçōes que permitam reconhecer com certeza máximos de freqüência nesse intervalo de tempo, embora o histograma de Gomes et al. (op. cit.) seja sugestivo nesse sentido por indicar dois agrupamentos, entre 125-145 Ma (Neocomiano) e 160-175 Ma (Meso a Neojurássico).

A presença do magmatismo permo-triássico, tal como se manifestou na Amazônia, ainda não está comprovada no Nordeste Oriental, embora uma datação K-Ar acusando 245 \pm 13 Ma figure na tabela fornecida por Gomes et al. (op. cit.), como dado inédito do Centro de Pesquisas Geocronológicas da USP (CPGeo). Tal valor é considerado por esses autores como idade anômala.

Formação Ipojuca Embora conhecidas desde os trabalhos de J.C. Branner do princípio do século, as rochas vulcânicas da costa a poucas dezenas de quilômetros a sul do Recife e o Granito do Cabo de Santo Agostinho (Fig. 6) só foram relacionados à mesma província magmática com a aplicação da geocronologia (Vandoros et al. 1966, Vandoros in Almeida et al. 1967).

As rochas vulcânicas que integram a Formação Ipojuca (Amaral \& Menor 1979) são ríblitos, traquitos, quartzo traquitos, andesitos, basaltos, comenditos e ankaramitos, constituindo uma série alcalina com tendência álcali-cálcica. Também ocorrem tufos, aglomerados e outros piroclastos, possivelmente equivalentes a mais de um centro vulcânico e talvez a mais de um episódio, o que a geocronologia e a insuficiência de mapeamentos de detalhe ainda não permitem distinguir.

Tais rochas constituem diques, plugs, derrames, soleiras e lacólitos penetrando nas rochas clásticas, cretáceas, da Formação Cabo (Cobra 1960, Borba 1975, Sial 1976a).

O Granito do Cabo de Santo Agostinho é uma variedade cálcio-alcalina destituída de mica, possuindo algum anfib́rlio sodico, especialmente arfvedsonita.

Borba (op. cit.), Borba \& Sial (1979), Long et al. (1986) e Sial et al. (1987) examinaram aspectos petrográficos e petroquímicos da pequena província magmática. Borba \& Sial (op. cit.) sugeriram ter o magma granítico se originado da fusão parcial da crosta inferior ou média. Admitem também a
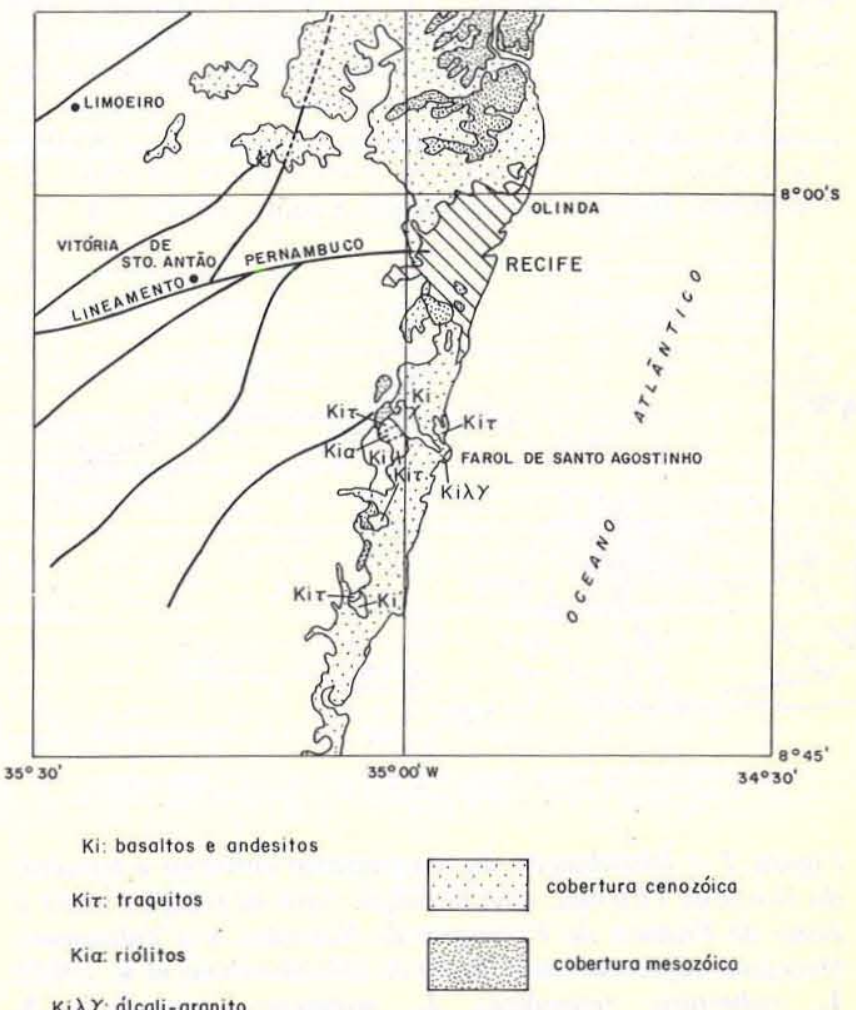

Ki $\lambda \gamma$ : ólcali-granito

Figura 6-Área de ocorrência da Formação Ipojuca (segundo Gava et al. 1983)

possibilidade de ter sido proveniente da diferenciação do magma basáltico, sem que tivessem chegado a uma conclusão final a respeito. Para Legrand \& Figueiredo Filho (1979), o Granito do Cabo de Santo Agostinho é constituído de dois tipos de rocha: um microssienito que se apresenta como xenólitos e o granito propriamente dito, que teria penetrado no anterior e seria de geração menos profunda. Considerando a baixa razão $\mathrm{Sr}^{87} / \mathrm{Sr}^{86}$, os autores julgaram que o granito proviria do manto. Reavaliaram os valores isotópicos das amostras analisadas, dividindo-os em duas isócronas, a mais nova correspondendo ao granito, que teria $104 \pm 0,8 \mathrm{Ma}$, enquanto os rí́litos teriam $135 \pm 0,7 \mathrm{Ma}$, porém essa diversidade de idades não condiz com a homogeneidde geocronológica do conjunto (Gava et al. 1983).

Gava et al. (op. cit.) reproduziram 20 datações isotópicas $\mathrm{Rb}-\mathrm{Sr}$ de dados do CPGeo, sendo três do trabalho de Vandoros et al. (op. cit.) recalculadas e também 10 dataçōes $\mathrm{K}-\mathrm{Ar}$ (recalculadas) contidas neste último trabalho. Os valores $\mathrm{Rb}-\mathrm{Sr}$ permitem construir uma boa isócrona, correspondente a $102,9 \pm 1,4 \mathrm{Ma}(\mathrm{Ri}=0,7073 \pm 0,0008)$, valor esse que condiz com as dataçōes $\mathrm{K}-\mathrm{Ar}$ disponíveis. Pode-se, portanto, considerar a província magmática como tendo aproximadamente $103 \mathrm{Ma}$, isto é, vinculada ao Neoalbiano.

$\mathrm{Na}$ porção interna do Platô de Pernambuco, a leste do Recife, existe um gráben em cujo interior, com base em interpretaçōes sísmicas, foram identificadas quatro unidades estratigráficas (Alves \& Costa 1986). Na inferior, denominada Unidade Estratigráfica I por esses autores, recente perfuração da Petrobrás realizada na parte costeira do gráben penetrou rochas ígneas básicas e/ou alcalinas cuja origem mais provável se liga à fase rift-valley (apud Alves \& Costa op. cit.). Os autores referidos consideram que a idade mais provável para a Unidade Estratigráfica I estaria compreendida entre o Neocomiano e o Albiano. Se assim for, o citado magmatismo seria anterior ao da Formação Ipojuca, datado do Neoalbiano. 
Vulcanismo Itapororoca O Vulcanismo Itapororoca tem suas rochas localizadas próximo à cidade homônima, na Paraíba. Segundo Barbosa \& Braga (1974) constitui-se de rocha porfirítica silicificada, vacuolar, com cristais de feldspato, que esses autores classificaram como tufo pórfiro. Tais rochas seriam do Cretáceo, possivelmente correlatas do Vulcanismo Ipojuca. Sua ocorrência é muito restrita (Fig. 7).

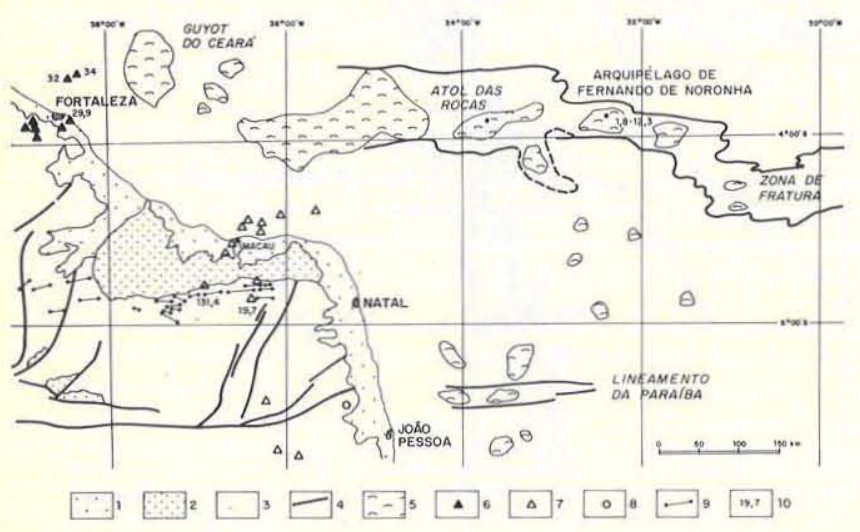

Figura 7 - Distribuição do magmatismo cretáceo e terciário do Nordeste Oriental, com destaque para as relações entre a Zona de Fratura de Fernando de Noronha, e o Vulcanismo Mecejana adjacente (modificado de Schobbenhaus et al. 1981): 1. cobertura cenozóica; 2 . sedimento mesozóico; 3. embasamento; 4. falha; 5. altos do embasamento acústico; 6. vulcanismo Mecejana; 7. vulcanismo Macau; 8. vulcanismo Itapororoca; 9. Magmatismo Rio Ceará-Mirim; 10. determinaçâo $K-A r(M a)$

Formação Macau As rochas basálticas pós-paleozóicas do Rio Grande do Norte e Paraíba foram originalmente tidas como representando um mesmo episódio vulcânico, porém mais tarde divididas em dois grupos maiores de idade por observações de campo e datações isotópicas. Kegel (1957) afirmou ser patente que na bacia costeira do Rio Grande do Norte os basaltos se estendem por cima da Formação Jandaíra, até o andar Maastrichtiano, e que, em vários lugares, como a sul de Macau, recobrem-se pela Formação Barreiras. Atribuiu-lhes, por isso, idade eo a mesoterciária, o que estudos geocronologicos viriam posteriormente confirmar. No trabalho de Kegel (op. cit.) incluem-se descriçőes petrográficas de E.P. Scorza, que classificou os basaltos da região de Macau e Salinópolis como olivina basaltos.

Mayer (1974) propôs a denominação Formação Macau para os derrames vizinhos à cidade homônima. Essa formação faz parte da coluna litoestratigráfica da Bacia Potiguar.

As rochas ígneas terciárias do Rio Grande do Norte e Paraíba constituem plugs, necks, derrame e diques de natureza alcalina. Acham-se dispostos numa faixa orientada proximamente a NNW-SSE, com cerca de $300 \mathrm{~km}$ de extensão por 80 de largura (Figs. 4 e 7), entre os derrames de olivina basalto de Queimadas, Boa Vista e Campos Novos, na Paraíba, e os dos campos marinhos de Ubarana e Agulha da Petrobrás, $40 \mathrm{~km}$ a NE de Macau.

As rochas do Vulcanismo Macau são predominantemente olivina basaltos, basanitos e ankaratritos (Sial 1976a), ocorrendo localmente nefelinitos (Rodrigues 1976). Derrames e diques tendem a se constituir de olivina basaltos, sendo os plugs e necks sobretudo de basanitos e ankaratritos.

Sial (1976b) fornece descrições mineralógicas e texturais das mais típicas ocorrências do Rio Grande do Norte e Paraíba, e discute a história da cristalização e a origem dessas rochas, que considera resultarem de câmara magmática situada à profundidade de $64 \mathrm{~km}$ ou superior, como determinou a investigação dos nódulos ultramáficos.

No trecho submerso da Bacia Potiguar, no Campo de Ubarana a nordeste de Macau, ocorrem olivina basaltos do Eoceno ao Mioceno, datados pela posição estratigráfica (Souza 1982). Us derrames se acham presentes nas formaçōes Tibau, Guamaré e Ubarana. Segundo Asmus (1984a e b), são rochas basálticas e piroclásticas confinadas a pequena área de cerca de $800 \mathrm{~km}^{2}$, com uma datação isotópica de $42 \mathrm{Ma}$, atingindo espessura máxima de até $1.500 \mathrm{~m}$, e que devem representar um centro vulcânico. É de se notar que na seção cretácea da coluna estratigráfica dessa bacia também ocorrem derrames basálticos do Eocretáceo com datação de $130 \mathrm{Ma}$ (Asmus \& Guazelli 1981), num alto do embasamento que a separa da Bacia de Pernambuco-Paraíba (Alto de Touros). Constituem derrames possivelmente correlacionáveis aos diques do Magmatismo Rio Ceará-Mirim. Verifica-se que, tal como no nordeste continental, também na área submersa apresenta-se vulcanismo basáltico de duas idades, eocretácea e terciária. Faltam informaçōes sobre a natureza química do vulcanismo submerso, até mesmo dados sobre as características petrográficas de muitas dessas rochas.

$\mathrm{Na}$ Paraíba, derrames de olivina basalto alcalinos ocorrem sobretudo em Boa Vista, Cubati e Queimadas (Fig. 8). Os primeiros se situam a sudeste da vila, no município de Campina Grande. Caldasso (1967) descreveu-os e Brito-Neves (1982) indicou possuírem idade de 29,5 $\pm 1 \mathrm{Ma}$.

A nordeste de Cubati ocorrem derrames de apreciável extensão de olivina basaltos alcalinos mapeados por Ennes \& Santos (1975, apud Dantas \& Caúla 1982). Brito-Neves (op. cit.) indica para essas rochas idade de $19,1 \pm 1$ Ma. Elas também ocorrem a sul de Queimadas, tendo sido datadas de $37 \pm 3 \mathrm{Ma}$ (Brito-Neves op. cit.). O mapa de anomalias magnéticas da figura 8 ilustra a vinculação entre várias das zonas anômalas identificadas com corpos conhecidos da Formação Macau. É notável também a subordinação das ocorrências e zonas anômalas com relação aos lineamentos aeromagnéticos, que em grande parte correspondem a falhas conhecidas. A posição do Lineamento de Patos está indicada na figura 8.

Um alinhamento de anomalias magnéticas tridimensionais, orientado segundo NNE, foi identificado na região de São Rafael (RN). Trata-se de uma região onde são raras as ocorrências conhecidas de corpos da Formaçäo Macau (Fig. 9). Uma particularidade dessa feição é o fato de desaparecer junto à Falha Portalegre-Carnaubais. Admite-se que esteja vinculada à evolução do magmatismo basáltico alcalino, porém as informaçōes são escassas.

Trabalho de Sial et al. (1981), além de outros citados por Gomes et al. (op. cit.), indica 18 datações isotópicas $\mathrm{K}-\mathrm{Ar}$ do Vulcanismo Macau com valores entre o Eoceno e o Mioceno. Fodor \& McKee (1986), datando amostras alteradas do poço submarino RNS-6-1 da Bacia Potiguar a ENE de Macau, obtiveram valores oligocênicos de $29,0 \pm 0,9$ e $36,3 \pm 1,0 \mathrm{Ma}$ pelo mesmo método.

Vulcanismo Mecejana Em 1958, Almeida investigou indícios de possível extensão ao continente do alinhamento de altos-fundos em que se encontram o Arquipélago de Fernando de Noronha e o Atol das Rocas, tendo então correlacionado ao alinhamento as rochas do Morro do Caruru, entre Aguiraz e Mecejana, a sudeste de Fortaleza (Fig. 7). Vandoros \& Oliveira (1968) foram os primeiros a descrevê-las, sob a denominação de Fonólito de Mecejana. Estudos posteriores (Rao \& Sial 1972, Bacchiesa et al. 1976, Braga et al. 1981, Nascimento et al. 1981) evidenciaram a existência de expressivo centro vulcânico alcalino oligocênico na região. Constitui-se de diversos necks e diques de rochas alcalinas encaixados nas rochas do embasamento cristalino.

Braga et al. (op. cit) descreveram diversos tipos de 


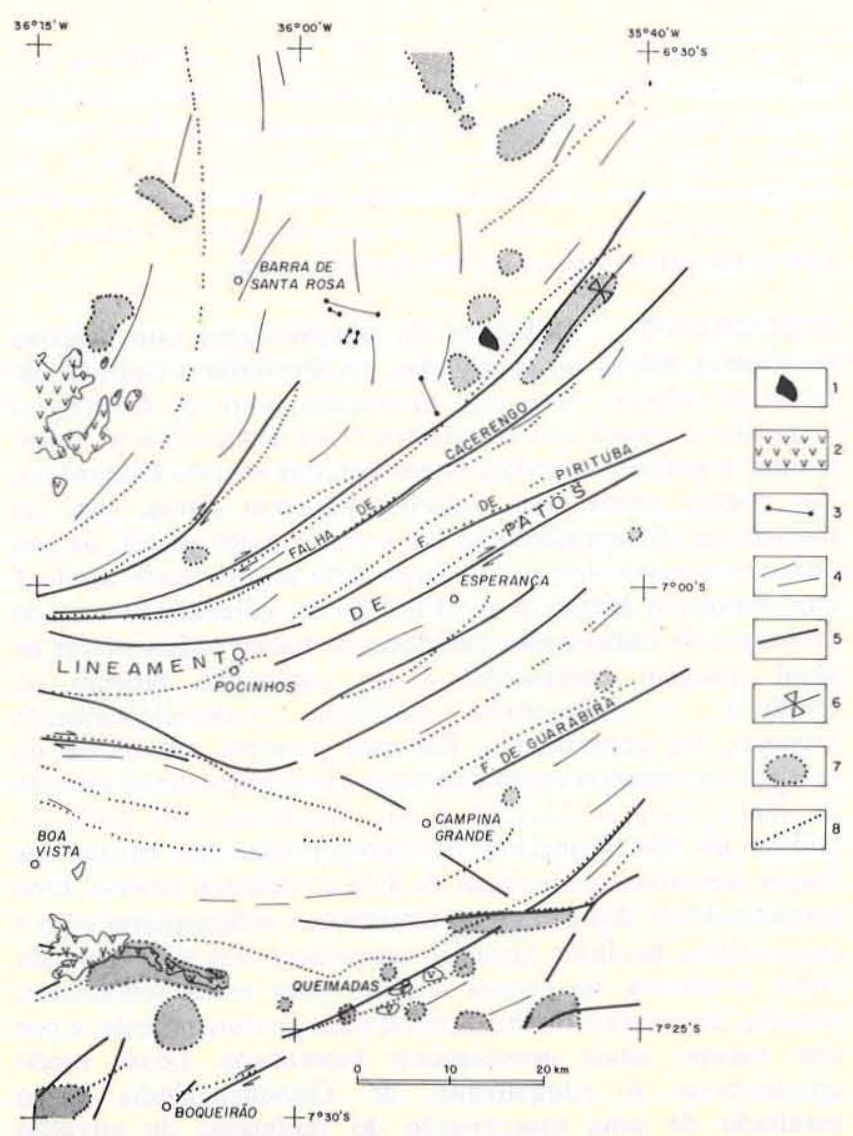

Figura 8 - Alinhamentos e zonas magnéticas anômalas na porção oriental do Lineamento de Patos: 1. rochas máficas pré-cambrianus, 2. olivina basaltos alcalinos da Formaçâo Macau; 3. dique básico; 4. alinhamento estrutural; 5. falhas; 6. sinforma; 7. zona anômala; 8 . alinhamento magnético

ocorrências e variedades petrográficas dessa pequena província magnática. Os fonólitos constituem necks que se mantêm em destaque topográfico. Seguem-se em importância os traquitos, que se apresentam como os diques mais espessos, sendo os demais de fonólito. Pequena área de essexito pórfiro parece representar um dique. Braga et al. (op. cit.) ainda referem a presença de tufos alcalinos associados a dois necks fonolíticos, assim como de analcitito e analcita traquibasalto sob forma de blocos soltos.

Nascimento et al. (op. cit.) apresentam outras informaçōes sobre o Vulcanismo Mecejana, principalmente quanto à sua mineralogia, petrografia e geocronologia. Uma isócrona $\mathrm{Rv}-\mathrm{Sr}$ em rocha total acusou $36 \pm 2 \mathrm{Ma}$, com quatro pontos bem ahuhados e um discrepante. Thomaz Filho (1983) se refere a uma datação $\mathrm{K}-\mathrm{Ar}$ em fonólito que acusou $32 \pm 1$ Ma. Cordani (1970) havia determinado a idade terciária do Fonólito Mecejana, por meio de $\mathrm{K}-\mathrm{Ar}$ em feldspato, encontrando 29,9 Ma. Nascimento et al. (op. cit.) transcreveram resultados de 19 análises químicas, incluindo análises de Vandoros \& Oliveira (op. cit.), Rao \& Sial (1972) e 12 originais, com base nas quais discutiram o quimismo dessas rochas ígneas. Os diversos autores que estudaram a petrografia, mineralogia e quimismo dessas rochas salientaram sua semelhança com as congêneres de Fernando de Noronha.

Vulcanismo Mundaú Na sub-bacia Mundaú, no trecho oriental da Bacia do Ceará e acima de sedimentos e rochas vulcânicas cretáceas, ocorre vulcanismo terciário representado por basaltos de natureza química e petrográfica ainda mal conhecidos.
Foram relatados inicialmente por Thomaz Filho (op. cit.) e Miranda et al. (1986). Propõe-se denominar provisoriamente esse conjunto de derrames de Vulcanismo Mundaú (Fig. 10). Amostras de calha dos poços 1-CES-29 e 1-CES-70 da Petrobrás, situados na direção $\mathrm{NE}$ da faixa de intrusōes alcalinas do Vulcanismo Mecejana, que é também a orientaçåo das estruturas do embasamento local, acusaram idades de 32 $\pm 1 \mathrm{Ma}$ (Thomaz Filho op. cit.).

Vulcanismo do Alto Atlântico Szatmari et al. (1987) se referem brevemente à existência de um vulcanismo de natureza riolítica de idade eocênica limitado ao Alto Atlântico, na sub-bacia Piauí-Camocim.

Rao \& Sial (op. cit.), ao compararem os fonólitos da regiâo de Fortaleza com os da Formação Remédios de Fernando de Noronha, referiram a consangüinidade entre eles e os respectivos magmas-fontes. Há, contudo, diferenças de idade, uma vez que os do arquipélago têm cerca de 8 a $11 \mathrm{Ma}$ (Cordani op. cit.). A diferença de nível de erosão não seria bastante para explicar tal diversidade cronológica.

Vulcanismo do Alto do Ceará O Alto do Ceará, que na bacia homônima separa as sub-bacias Piauí-Camocim e Acaraú, foi reinterpretado por Zalán \& Warme (1985) em decorrência da recente sondagem CES-87. Ela atravessou seção com pelo menos $1.600 \mathrm{~m}$ de espessura, na qual se observam conglomerados e brechas que contêm fragmentos de rochas vulcânicas félsicas e de granito. Zalán \& Warme

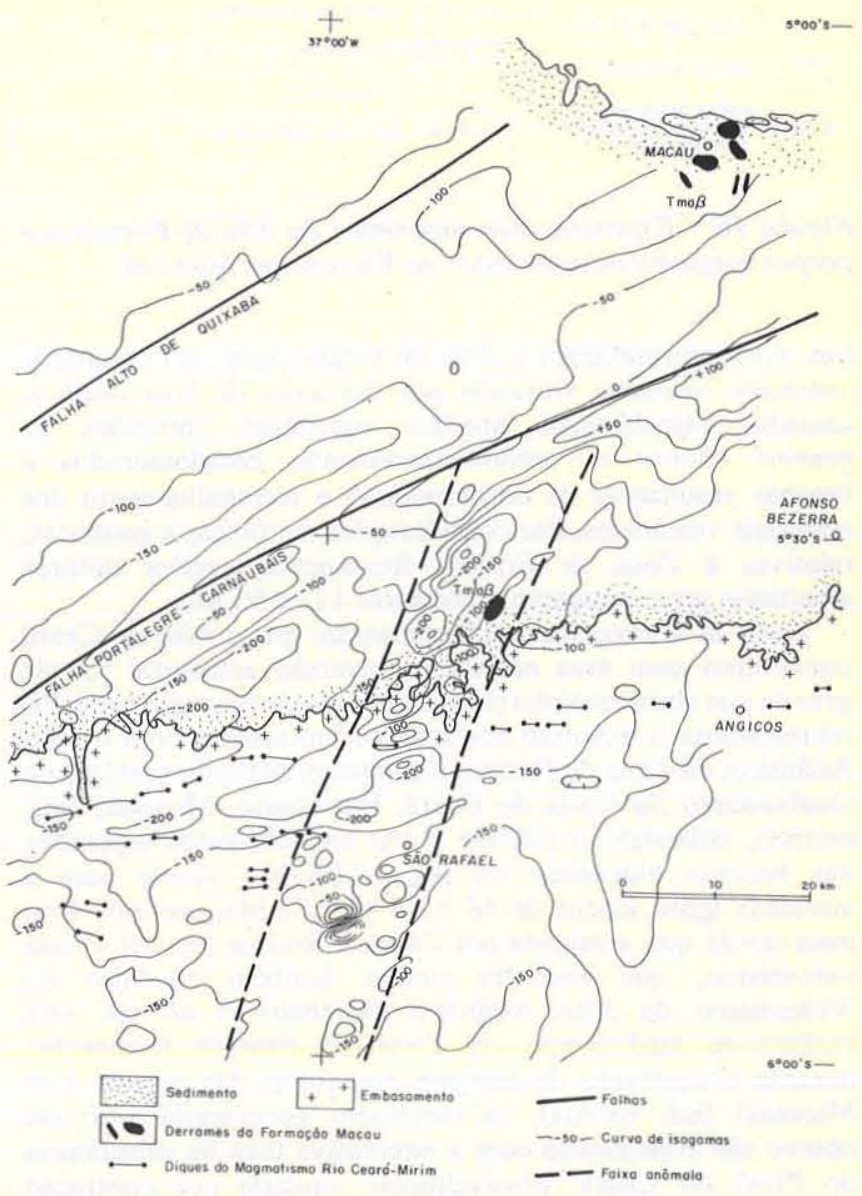

Figura 9 - Alinhamento de anomalias tridimensionais a SW de Macau afetando a área cristalina e o embasamento raso da Bacia Potiguar 


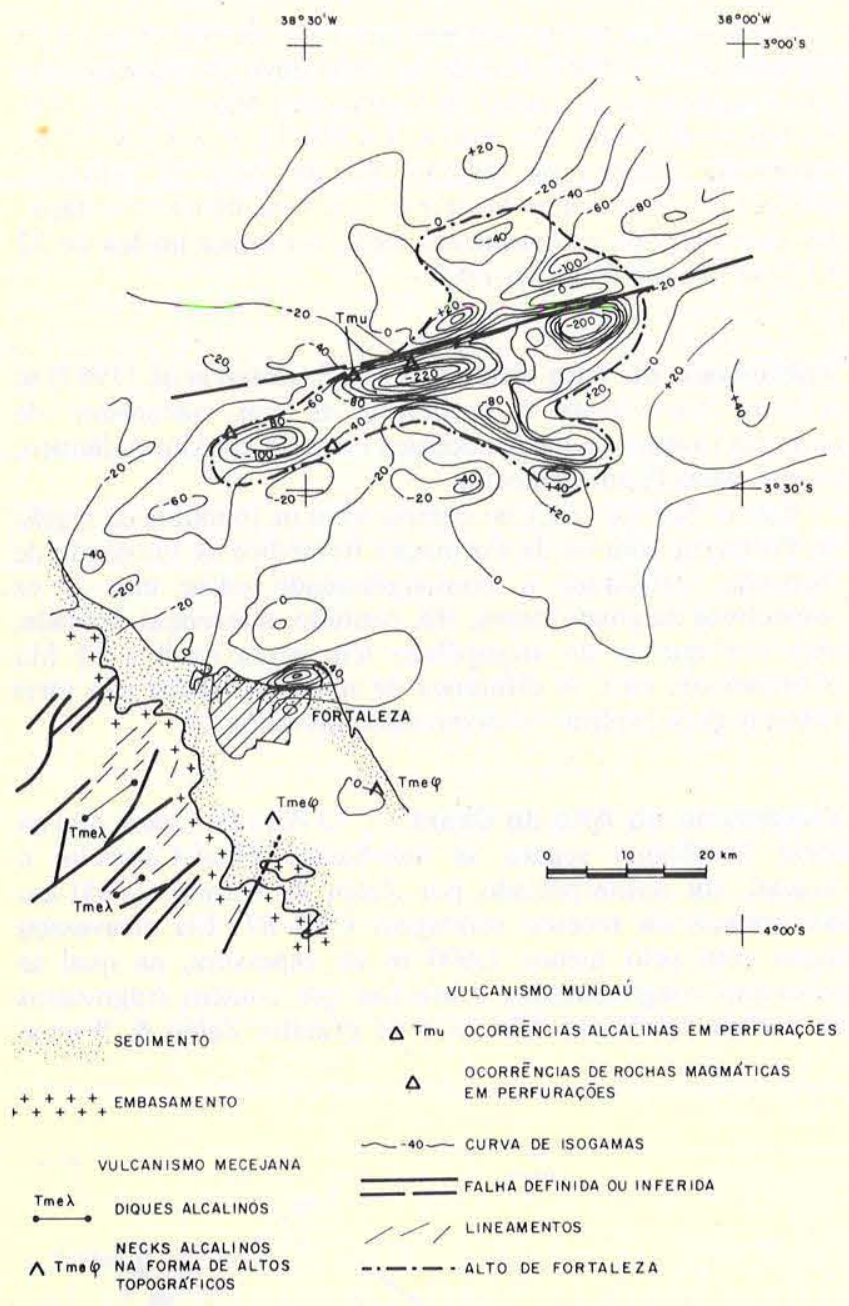

Figura 10 - Expressão aeromagnética do Alto de Fortaleza e corpos magmáticos associados ao Vulcanismo Mundaú

(op. cit.) interpretaram o Alto do Ceará como um complexo vulcânico-intrusivo formado por derrames de lava riolítica, camadas piroclásticas, brechas vulcânicas, intrusões de granito, diques e, predominantemente, conglomerados e brechas resultantes de decomposiçaō e retrabalhamento dos materiais vulcânicos. Por considerações tectônicas e genéticas, relativas à Zona de Fratura Romanche, aqueles autores admitiram ter o complexo idade entre 112 e $95 \mathrm{Ma}$.

Zalán \& Warme (op. cit.) supuseram que o Alto do Ceará constituiria uma área em que a inversão estrutural foi tão grande que abriu caminho para a ascensão de magma crustal. Ela representaria a extensão continental, juntamente com o Alto Atlântico, da Zona de Fratura Romanche, durante o estágio de cisalhamento da Bacia do Ceará. Entretanto, Mizusaki (inf. escrita), utilizando o método $\mathrm{K}$-Ar em feldspatos separados das brechas vulcânicas do poço CES-87, obteve para a atividade ígnea idades de $44 \pm 3$ e $43 \pm 12 \mathrm{Ma}$, portanto bem mais novas que a suposta por Zalan \& Warme (op. cit.). Esse vulcanismo, que encontra similar também eocênico no Vulcanismo de Alto Atlântico (Szatmari et al. op. cit.), realizou-se tardiamente na Zona de Fratura Romanche, durante compressão da margem equatorial. De acordo com Mizusaki (inf. escrita), os resultados geocronológicos que obteve são condizentes com a expressiva taxa de subsidência do Platô do Ceará, possivelmente causada por contração térmica de um evento magmático situado no Eoceno-Oligoceno, conforme detectado por Costa \& Kowsmann (1981).

Na Bacia Piaú-Camocim, segundo Zalán \& Warme (op. cit.) e Zalán et al. (1985, figura 7a, p.182), observa-se um magmatismo básico de idade Alagoas Inferior, relacionado ao estágio rifte de evolução da margem equatorial. Tais rochas foram truncadas pela discordância pós-rifte, ao final do Alagoas Inferior. Caso confirmada essa idade, seria este o único exemplo ora conhecido, de extensão até o Aptiano, da fase magmática toleítica do Nordeste Oriental.

DISCUSSÃO Relações do magmatismo com feições tectônicas ativas ou reativadas no Mesozóico-Cenozóico. Diversas relações têm sido apontadas entre os fenômenos magmáticos mesozóico-cenozóicos e feições tectônicas, sejam antigas e então reativadas, sejam geradas no pós-Paleozóico. Em poucos casos essas relações parecem claras, mas na maioria ou são apresentadas em termos muito gerais, ou são puramente especulativas. $\mathrm{O}$ único fato seguramente aceito que durante o Jurássico e o Eocretáceo, coincidindo com os processos de falhamentos geradores de bacias sedimentares na atual margem continental e no continente emerso no Nordeste, o magmatismo basáltico, predominantemente toleítico, foi generalizado. Ele está presente nas bacias da margem continental como derrames e intrusões, mas é ausente na Bacia Sergipe-Alagoas e nas vizinhanças da costa do Cráton do São Francisco. Só excepcionalmente ocorre nas bacias mesozóico-cenozóicas da área continental emersa. Essa simultaneidade dos processos tectônicos e sedimentares com o magmatismo basáltico jurássico-eocretáceo tem sido apontada como evidência de causas comuns para esses fenômenos, situadas no interior da litosfera ou mais profundamente, e por isso mesmo ainda grandemente hipotéticas. Desse modo apresenta-se o rompimento de Gonduanalândia como resultado de uma exacerbação do fenômeno de ativação tectono-magmática mesozóica decorrente de um evento térmico no Manto.

O magmatismo e as estruturas pré-cambrianas São vários os exemplos que têm sido bem comprovados de reativação de antigas falhas e zonas de cisalhamento pré-cambrianas da região. Embora o tempo de maior intensidade desse processo coincida com o do magmatismo basáltico toleítico, são poucas as estruturas dessa idade na região que sofreram infiltrações magmáticas. A Bacia de Lavras da Mangabeira é um desse casos noticiados. Possui corpos tabulares, soleiras ou derrames (?) concordantes com a Formação Antenor Navarro e situa-se entre falhas da zona de cisalhamento do grande Lineamento de Patos. No extremo ocidental exposto deste lineamento, na região de Barra (CE), também há magmatismo máfico (informação pessoal de B.B. de Brito-Neves). Na Figura 8 é sugestivo o envolvimento de estruturas desse importante lineamento nordestino na evolução dos corpos ígneos terciários da região entre Campina Grande e Queimadas.

A área do Cráton de São Francisco foi poupada pelas intrusões magmáticas fanerozóicas, embora elas não sejam inteiramente ausentes (Almeida 1986). O Gabro de Curaçá (BA) faz parte de um sistema de diques paralelos situados junto à borda do cráton, na Bahia. Foi datado de $73 \mathrm{Ma}$ (Cordani 1970). A figura 11 ilustra a posição de um desses diques.

Santos \& Brito-Neves (1984), citando Costa et al. (1973) e Sial (1975), referem que na projeção para o substrato da Bacia do Parnaíba, dos lineamentos de Sobral e de Patos são encontradas várias emanações de rochas máficas como expressão da Reativação Wealdeniana.

Kowsmann \& Costa (1976) sugeriram que as irregularidades topográficas do embasamento sísmico do Platô de Pernambuco, recobertas pelo Neocretáceo-Cenozóico, representam um relevo vulcânico. Por se situar o platô no prolongamento do Lineamento de Pernambuco, é admissível supor que o vulcanismo que se lhe associa, e do qual a Formação Ipojuca seria uma projeção, tivesse se originado da 


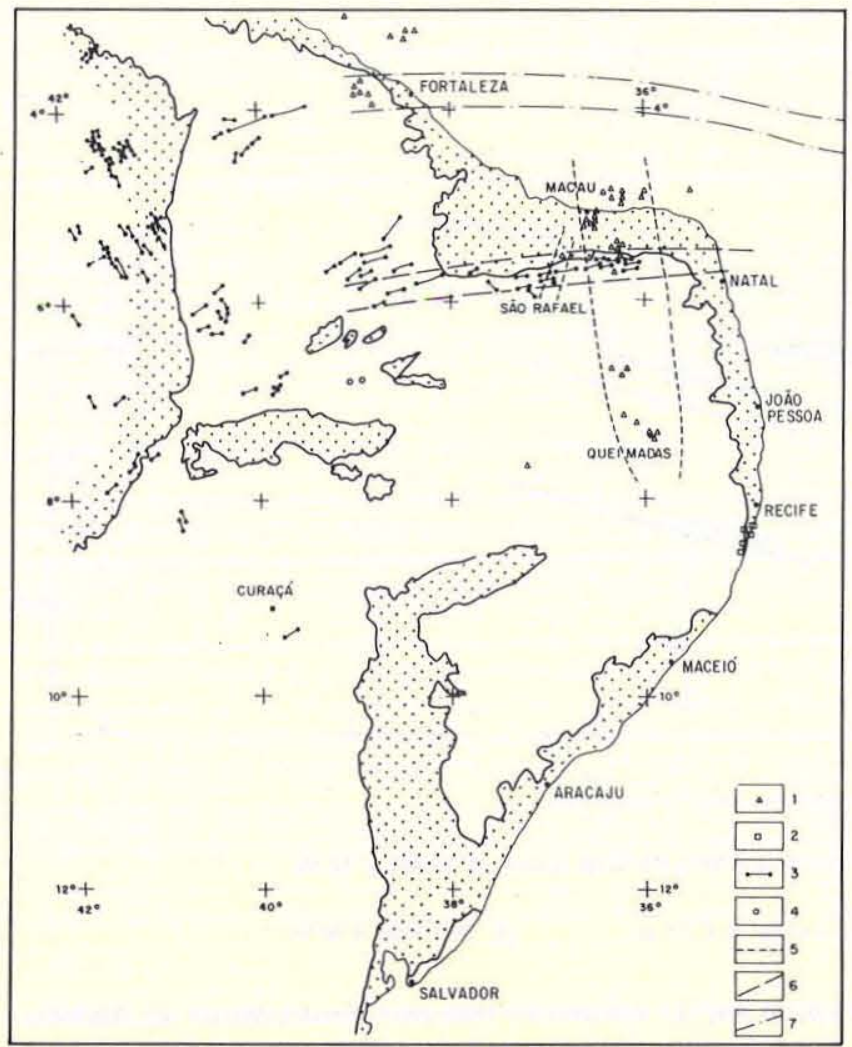

1. TERCIÁRIO; 2. CRETÁCEO; 3. JURO-CRETÁCEO (DIOUES); 4 JURO-CRETÁCEO (SOLEIRAS); 5. ALINHAMENTOS MACAU - QUeIMADAS E OE SÁo RAFAEL, 6. ALINHAMENTO RIO CEARÁ-MIRIM, 7. ALINHAMENTO MECEJANA-FERNANDO DE NORONHA.

Figura 11 - Atividade tgnea pós-paleozóica no Nordeste e alinhamentos relacionados: 1. Terciário; 2. Cretáceo; 3. Juro-Cretáceo (diques); 4. Juro-Cretáceo (soleira); 5. alinhamentos Macau-Queimadas e de São Rafael; 6. alinhamento Rio Ceará-Mirim; 7. alinhamento Mecejana-Fernando de Noronha

reativação desse lineamento. Asmus \& Carvalho (1978) também associam ao alinhamento os Montes Submarinos de Pernambuco.

O magmatismo e as grandes estruturas mesozóico-cenozóicas Os feixes de diques do Magmatismo Rio Ceará-Mirim no Rio Grande do Norte põem uma questão muito importante. Não ocupam zonas pré-cambrianas ou mais novas de fraqueza crustal reconhecíveis nos mapeamentos executados. Por serem paralelos à costa lembram os diques de mesma idade da região da Serra do Mar face à Bacia de Santos. Um arqueamento do tipo flexura continental, sugerido por Santos (1968) e Fortes $(1984,1986)$ para a Bacia Potiguar, constituiria modelo análogo ao proposto por Almeida (1976) para explicar o vulcanismo da área emersa adjacente à Bacia de Santos. Há, contudo, diferenças importantes a notar, sobretudo no que se refere ao nâo-paralelismo dos diques e do traçado da linha-de-costa às estruturas do embasamento ou às orientadas a ENE da Bacia Potiguar.

Sial (1976a) sugeriu ter sido a colocação dos diques de diabásio sublatitudinais uma conseqüência da deriva do continente sul-americano em relaçåo ao africano. Nota que, se os mapas da América do Sul e África forem convenientemente justapostos, o referido sistema de diques estaria em aparente continuidade com o eixo da Fossa de Benuê na Nigéria, cuja idade de abertura coincide aproximadamente com a origem daquele sistema de diques. $\mathrm{Na}$ fossa de Benuê há algumas intercalações de basaltos supostos mesocretáceos, mas sảo de natureza alcalina e mais novos que estes do Rio Grande do Norte. Na Nigéria, entretanto, refere Sial (1976, citando McCurry et al. 1976, com. escrita), também ocorrem basaltos toleíticos mesojurássicos a eocretáceos, similares aos do Rio Grande do Norte em idade e características químicas.

Françolin \& Szatmari (1987) consideram ter-se dado a rotação horária do continente ao redor de um pólo localizado aproximadamente a $39^{\circ} \mathrm{WG}$ e $7^{\circ} \mathrm{S}$, o que causaria na Província Borborema, durante o Ncocomiano, a norte do lineamento de Pernambuco, uma compressåo de direção leste-oeste e uma distensão norte-sul. Esse regime de esforços formaria falhas normais e reativaria falhas antigas de direção aproximadamente leste-oeste. $\mathrm{O}$ sistema de diques Rio Ceará-Mirim decorreria dessas condiçōes dinámicas, constituindo extenso alinhamento (Fig. 11). As falhas orientadas a NE-SW preexistentes teriam sido entâo reativadas por movimentos transcorrentes dextrais, com movimentação transtensional em seu extremo próximo à costa e transpressional nas porçőes mais internas do continente. $\mathrm{O}$ referido sistema de diques assinalaria o limite entre os dois regimes.

Vários autores têm mencionado as semelhanças do complexo magmático representado pelos "granitos jovens" da Nigéria, Níger e Costa do Marfim com as rochas vulcânico-plutônicas da Formação Ipojuca. Para Sial (1976a), parece provável que, ao se iniciar o afastamento dos continentes entre 90 e $110 \mathrm{Ma}$, o complexo magmático da Formaçảo Ipojuca estaria aproximadamente onde hoje se encontra a Ilha de Ascensâo. De tal modo a Pluma de Ascensão poderia estar ativa nessa ocasião, causando fraturas tracionais na litosfera acima dela, pelas quais ascenderia o magma basáltico, sendo aprisionado durante algum tempo na crosta, que em parte se teria fundido. Essa fusảo teria originado líquidos graníticos que se introduziriam nas fraturas, produzindo inicialmente riólitos.

$\mathrm{O}$ pequeno distrito vulcânico alcalino representado pela Formação Mecejana situa-se numa posição tectônica particular na área emersa, na projeção de uma zona de fraturas oceânicas de direção sublatitudinal (Fig. 7), na qual se localizam diversos montes submarinos, o Atol das Rocas, o Arquipélago de Fernando de Noronha e rochas do Vulcanismo Mundaú, na Bacia do Ceará (Miranda et al. 1986). Almeida $(1956,1960)$ atribuiu esse alinhamento a uma zona de fraturas oceânicas em que o vulcanismo progrediu de oeste para leste, ao longo da cadeia (Fig. 11), o que de certo modo concorda com as informações geocronológicas. Estudos de Cordani (1970), Rao \& Sial (1972), Gorini \& Bryan (1976) apóiam essa correlação. Sykes (1978) cita-a como um exemplo, entre muitos outros que refere, da presença de magmatismo alcalino na extensão continental de falhas transformantes oceânicas.

$\mathrm{O}$ distrito intrusivo-efusivo félsico representado pelos vulcanismos do Alto Atlântico e do Ceará alinha-se a E-W dentro da Zona de Fratura Romanche, parecendo indicar sua extensão continental, como admitiram Zalán \& Warme (1985). Constituiria de tal modo uma réplica da situação tectônica da Formação Macejana em relação à Zona de Fratura de Fernando de Noronha.

$\mathrm{O}$ vulcanismo representado pela Formação Macau ainda nảo recebeu uma explicação satisfatória. Desenvolveu-se quando os continentes já se achavam amplamente afastados (Fig. 12) e portanto não se manifestou em associação com a abertura do Atlântico Sul. Orienta-se submeridianamente (Fig. 11) sem quaisquer relações aparentes com estruturas pré-cambrianas ou desenvolvidas no Mesozóico e Cenozóico. na Bacia Potiguar. É expressivamente paralelo à costa oriental do Rio Grande do Norte e da Paraíba. Tem natureza predominantemente alcalina, sendo de origem mantélica, a julgar pela presença de nódulos de espinélio lherzolito inclusos em seus ankaratritos, que permitiram a Sial (1974) calcular ter provindo o magma de uma profundidade mínima de $64 \mathrm{~km}$. 


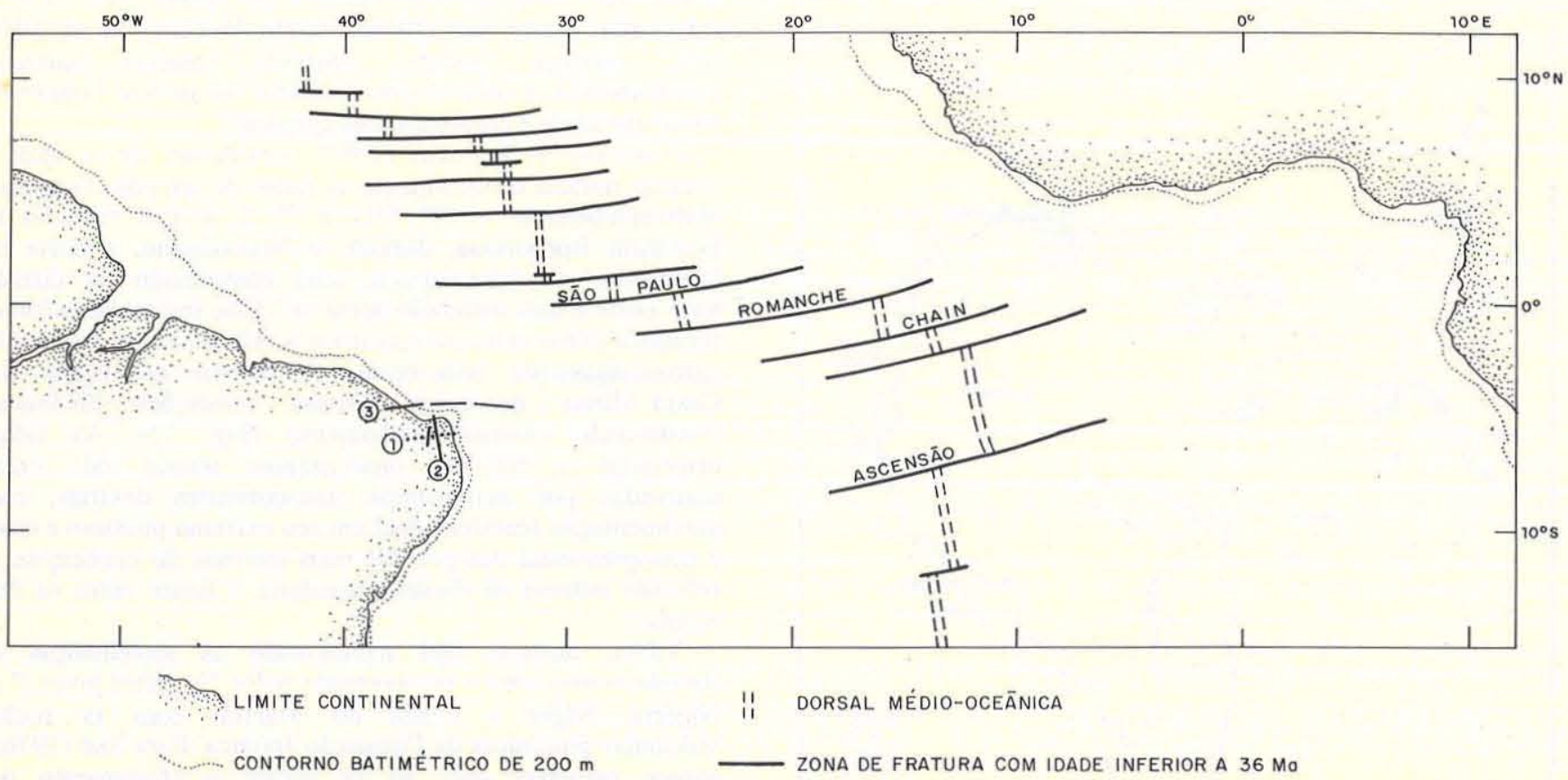

IDADES DE MAGMATISMO: (1) ENTRE 130 E $140 \mathrm{Mo}$

$\begin{array}{ll}\text { (2) ENTRE } 19 \mathrm{E} 37 \mathrm{Ma} & \text { (3) INFERIOR A } 30 \mathrm{Ma}\end{array}$

Figura 12 - Posiçâo aproximada dos alinhamentos ígneos em relação a feiçôes estruturais mioceno-pleistocênicas do Atlântico Equatorial (adaptado de Sibuet \& Mascle 1978)

Pela orientaçẩo da faixa de intrusōes, considerando a direção de deslocamento da placa e a falta de arranjo cronológico dos centros magmáticos, a possibilidade de uma explicação do Vulcanismo Macau por hot spots parece ficar excluída.

Durante a evolução do Vulcanismo Macau, as coberturas juro-cretáceas e outras mais antigas, porventura existentes no Nordeste, já se achavam em maior parte destruídas pela erosão. $\mathrm{O}$ vulcanismo se manifestou principalmente sobre assoalho pré-cambriano. A Bacia Potiguar, já então bem estruturada, possuía um centro vulcânico submarino de área restrita, que persistiu durante a deposição da seqüência transgressiva Ubarana e das regressivas Guamaré e Tibaú, do Oligoceno e Mioceno. Todos esses centros de intrusōes e emissões vulcânicas ora conhecidos acham-se alinhados numa faixa de direção submeridiana (Fig. 11), aqui denominada Alinhamento Macau-Queimadas. Esta ${ }^{-}$feiçâo havia sido notada por Sial (1976a).

Pode-se especular que a Formação Macau se tenha originado de uma crista térmica surgida no manto litosférico. Talvez em decorrência do deslocamento da placa para oeste, mas faltam razões ponderáveis que suportem essa idéia. Anomalias magnéticas expressivas, similares às representadas na figura 9 , porém com distribuição mais extensiva e afetando zonas largas da ordem de $50-60 \mathrm{~km}$, foram identificadas pelo IPT (1988) na região. Os estudos efetuados, no entanto, ainda não permitem precisar as profundidades em que se situam as feições que as originaram. Sial (1976a) admitiu a possibilidade de as zonas de fraqueza se terem formado na borda dos continentes em separação, como resultado do drifte. A mudança da velocidade de espalhamento do assoalho oceânico durante o Mioceno, concomitantemente com a Orogenia Andina, poderia causar reajustamentos na placa Sul-Americana e originar esse vulcanismo. Há que se lembrar também a possivel influência de tensôes originadas com a mudança do pólo de rotação durante o Terciário. De todo o modo, chama atençåo a singularidade do fenômeno magmático.
CONCLUSÕES Na evolução pós-paleozóica do Nordeste Oriental do Brasil são identificados três eventos magmáticos de distribuição hoje dispersa, mas que atingiram grande parte da área continental e da margem oceânica adjacente:

a. A atividade juro-cretácea se estendeu ao longo de toda a região afastada do Cráton do São Francisco, com natureza toleítica (Formação Sardinha, Magmatismo Rio Ceará-Mirim, Vulcanismo do Alto de Touros e da base da Bacia do Ceará).

b. Os registros aptianos e albianos se limitaram às áreas costeiras e regiōes submersas: a sul do Recife (Formaçao Ipojuca), a NW de João Pessoa (Vulcanismo Itapororoca) e no Alagoas Inferior da Sub-bacia Piaú-Camocim. $O$ de Itapororoca é de datação ainda incerta.

c. O magmatismo terciário, desenvolvido entre o Eoceno e o Mioceno, teve distribuição mais expressiva que o anterior, porém ainda limitado a uma faixa de largura inferior a uma e meia centena de quilômetros da costa. Em parte, as rochas vulcânicas se acham intercaladas com sedimentos costeiros e da área submersa adjacente. Pertencem à Formação Macau, Vulcanismos Mecejana, Mundaú, do Alto Atlântico e do Alto do Ceará.

As rochas dos três grupos de idade são distintas quanto à composição: as do primeiro são de natureza essencialmente toleítica; no segundo, destacam-se tipos félsicos, e no último, mais recente, são de tendência alcalina. Há registros de vulcanismo riolítico na região do Alto Atlântico e no Alto do Ceará, que pertencem ao terceiro grupo.

As atividades magmáticas paleogêni-as das regiōes sudeste e centro-oeste do país parecem representar manifestações tardias do importante magmatismo alcalino neocretáceo. Não é este o caso do vulcanismo alcalino ierciário do Nordeste, que constitui um episódio autônomo.

A expressão de zonas magmáticas anômalas e algumas anomalias lineares se mostrou valiosa como meio de identificação de corpos rasos ou subaflorantes da atividade 
ígnea mesozóico-cenozóica. Diversas ocorrências antes insuspeitadas acham-se indicadas em IPT (1988) e neste trabalho, com base em interpretações geofísicas.

Vários autores têm enfatizado a existência de alinhamentos de corpos ígneos mesozóico-cenozóicos. Relacionaram-nas a intervalos temporais e a situações geológicas diferenciadas entre si. $\mathrm{O}$ alinhamento Macau-Queimadas, aqui formalmente definido, orientado a NNW, possui extensão superior à inicialmente admitida por Sial (1976b).

A interpretação da origem do fenômeno esbarra em dificuldades como a aparente falta de vínculo entre os alinhamentos e as falhas geológicas mapeadas. A influência de estruturas do embasamento foi provavelmente importante nos episódios entre o final do Jurássico e o Neocomiano, mas, no caso dos derrames e intrusões mais novos, tais relações não são tão claras no estágio atual das investigações.
Agradecimentos A realização deste estudo recebeu o incentivo do DNPM e Petrobrás, que forneceram numerosos mapas e relatórios inéditos. Nesse sentido, os autores agradecem ao Dr. Carlos Oiti Berbert, do DGM/DNPM, e aos geólogos do Departamento de Exploração da Petrobrás, Drs. Giuseppe Bacoccolli, Marco Pólo Pereira da Boa Hora e Laércio Gonzaga de França Aranha. Os autores agradecem ainda as sugestões e os comentário sobre o manuscrito feitos pela geóloga Ana Maria Pimentel Mizusaki, da Divisão de Exploração do Cenpes, que forneceu vários dados ainda inéditos. A elaboração do trabalho foi muito auxiliada pela participação do assistente-aluno Ronaldo Malheiros Figueira. Os desenhos foram preparados pela Sra. Mirna Mancini Ferracini. A estas pessoas e entidades, bem como ao IPT, que forneceu os meios e o indispensável apoio ao projeto, os autores registram sua gratidão.

\section{REFERÊNCIAS BIBLIOGRÁFICAS}

AGUIAR, G.A. 1969. Bacia do Maranhão: geologia e possibilidade de petróleo. Belém, Petrobrás/Renor. 57 p. (Petrobrás Rel. 371)

ALMEIDA, F.F.M. de. 1958. Geologia e petrologia do Arquipélogo de Fernando de Noronha. Rio de Janeiro, DGM/DNPM. 158p. (Monografia 13)

ALMEIDA,F.F.M. de. 1960. Quelques aspects sous-marins au large de la côte brésilienne. In: INTERN. GEOL. CONGR., 21, Norden, 1960. Rapports... Copenhagen. part 10. p.23-28. (Submarine Geology)

ALMEIDA, F.F.M. de. 1976. The system of continental rifts bordering the Santos Basin, Brazil. An. Acad. bras. Ciênc., 48(supl.):15-26. (Proc. Intern. Symp. on Continental Margins of Atlantic type, October 1975)

ALMEIDA, F.F.M. de. 1983. Relaçōes tectônicas das rochas alcalinas da região meridional da plataforma sul-americana. Rev. Bras. Geoc.; 13(3):139-158.

ALMEIDA, F.F.M. de. 1986. Distribuição regional e relações tectônicas do magmatismo pós-paleozóico no Brasil. Rev. Bras. Geoc.; 16(4):325-349.

ALMEIDA, F.F.M. de.; LEONARDOS Jr., O.H.; VALENÇA, J. 1967. Granitic rocks of the North East South America. In: FIELD SYMPOSIUM ON THE GRANITES AND BASEMENT OF NORTH-EASTERN BRAZIL AND THEIR COMPARISON WITH OF WEST AFRICA, Recife, IUGS/UNESCO, 1967. (Spec. Publ....) Recife. $41 \mathrm{p}$.

ALVES, E.C. \& COSTA, M.P.A. 1986. Interpretação sismo-estratigráfica da porção norte do Platô de Pernambuco e suas possíveis correlações com a Bacia de Pernambuco-Paraíba. In: CONGR. BRAS. GEOL., 34, Goiânia, 1986. Anais... Goiânia, SBG. v.1, p.286-297.

AMARAL, A.J.R. \& MENOR, E.A. 1979. A seqüência vulcano-sedimentar cretácea na região de Suape (PE): Interpretação faciologica e considerações metalogenéticas. In: SIMP. GEOL. NORDESTE, 9, Natal, 1979. Atas... Natal, SBG/NNE. p. 251-269 (Bol. 7).

ASMUS, H.E. 1984a. Inferências, hipóteses e problemas relativos à origem e evolução da margem continental brasileira. In: CONGR. BRAS. GEOL., 33, Rio de Janeiro, 1984. Anais... Rio de Janeiro, SBG. v. 4, p. 1655-1677.

ASMUS, H.E. 1984b. Geologia da margem continental brasileira. In: SCHOBBENHAUS, C.; CAMPOS, D.A.; DERZE, G.R.; ASMUS, H.E., eds. Geologia do Brasil. Brasília, DNPM. p. 443-472.

ASMUS, H.E. \& CARVALHO, J.C. 1978. Condicionamento tectônico da sedimentação nas bacias marginais do Nordeste do Brasil (Sergipe/Alagoas e Pernambuco/Paraíba). In: PETROBRÁS Aspectos estruturais da margem continental leste e sudeste do Brasil. Rio de Janeiro, Petrobrás/Cenpes/Dintep. p. 7-24 (Projeto Remac 4)

ASMUS, H.E. \& GUAZELLI, M. 1981. Descrição sumária das estruturas da margem continental brasileira e das áreas oceânicas e continentais adjacentes, hipóteses sobre o tectonismo causador e implicaçöes para os prognósticos de recursos minerais. In: PETROBRÁS Estruturas e tectonismo da margem continental brasileira, e suas implicaçōes nos processos sedimentares e na avaliação do potencial de recursos minerais: relatório final. Rio de Janeiro, Cenpes/Dintep. p. 187-269. (Projeto Remac 9)

BACCHIESA, I.F. et al. 1976. Projeto Fortaleza; relatório da etapa de campo I. Recife. DNPM/CPRM. 84p. (Rel. Arq. Tec. DGM 2570)

BARBOSA, A.J. \& BRAGA, A.P.G. 1974. Projeto Oeste da Parabae Rio Grande do Norte; Rel. Final interpretado. Recife, DNPM/CPRM. 4.v.
BORBA, G.S. 1975. Rochas vulcânicas da faixa costeira sul de Pernambuco - Aspectos petrológicos e geoquímicos. Rio de Janeiro, 134 p. (Dissert. Mestrado, Inst. Geoc, Univ. Fed.).

BORBA, G.S. \& SIAL, A.N. 1979. Estudo petrológico e petroquímico do granito do Cabo de Santo Agostinho, PE. In: SIMP. GEOL. NORDESTE, 9, Natal, 1979. Atas... Natal, SBG/NNE. p. 305-316.

BRAGA, A.P.G. et al. 1977. Projeto Fortaleza. Rel. Final. Recife DNPM/CPRM. 10 v. (Rel. Arq. Tec. DGM 2653)

BRAGA, A.P.G. et al. 1981. Geologia da regiäo nordeste do Éstado do Ceará. Projeto Fortaleza. DNPM/CPRM. Brasília, 123 p. (Geologia 12, Seção Geologia Básica 9).

BRAUN, O.P.G. 1969. Geologia da Bacia do Rio do Peixe-Nordeste do Brasil. Rio de Janeiro, Prospec/DNPM. 23p. (Rel. Int.)

BRITO-NEVES, B.B. de 1982. Síntese da geocronologia. In: MAPA Geológico do Estado da Paraiba; texto explicativo. SERM/CDRM, Campina Grande, p. 55-69.

CALDASSO, A.L. da S. 1967. Geologia da quadrícula E-093, Folha Crato. Recife, Sudene/Div. Geologia. 39 p.

CAMPOS, C.V.M. 1964. Estratigrafia das bacias paleozóicas e cretáceas do Maranhão. Bol. Tec. Petrobrás, 7(2):137-164. (Trad. cond. de MESNER, J.C. \& WOOLDRIDGE 1962).

CARNEIRO, C.D.R.; MONMA, R.; FERREIRA, F.J.F; MAGALHÂES, F.S. 1988 Ensaio de interpretação geológico-geofísica do Nordeste Oriental com base nos mapas aeromagnéticos. In: CONGR. BRAS. GEOL., 36. Belém. 1988 Anais... Belém, SBG. (submetido)

COBRA, R.Q. 1960. Geologia da região do Cabo de Santo Agostinho, Pernambuco. Belo Horizonte, 43 p. (Tese de Doutoramento, UFMG).

COMPANHIA DE PESQUISA DE RECURSOS MINERAIS/GEOFOTO - CPRM/Geofoto. 1977. Projeto Aerogeofísico Cariris Velhos; mapas escalas $1: 100.000$ e 1:250.000. CPRM/Geofoto.

CORDANI, U.G. 1970. Idade do vulcanismo do Oceano Atlântico Sul. Gol.IGA, 1:9-75.

COSTA, M.C.; FRANÇA, J.B. de ; LINS, C.A.C.; BACCHIESA, I.F.; HABEKOST, C.R. 1973. Projeto Jaibaras; relatorio final. Recife DNPM/CPRM. (inédito)

COSTA, M.P.A. \& KOWSMANN, R.O. 1981. Tectonismo vertical no Pós-Paleogeno no Platô do Ceará e suas possíveis implicações. Bol. Tec. Petrobrás, 24(1):23-32.

DANTAS, J.R.A. \& CAÚLA, J.A.L. 1982. Estratigrafia e tectônica. In: SERM/CDRM. Mapa Geológico do Estado da Paratba; texto explicativo. Joảo Pessoa, SERM/CDRM. 134 p.

EBERT, H. \& BROCHINI, M.F. 1968. Estudos estrtigráficos geocronológicos no Escudo Cristalino Brasileiro. Ci. Cult., 20(3):621-625.

ENNES, E.R. \& SANTOS, J.S.A. 1975. O Projeto Piaú; relatório final. Recife, CNEN/CPRM. 2 v.

FODOR \& McKEE, E.H. 1986. Tertiary basaltic rocks from offshore northeastern Brazil. Geochemistry and K-Ar ages. An.Acad. bras., Ciênc., 58(2):233-241.

FORTES, F.P. 1984. O Pré-Cambriano $e$ as rochas básicas na Tectônica da Bacia Potiguar, parte emersa. Natal, Petrobrás/Depex/Debar/Dintep. 35 p.

FORTES, F.P. 1986. A tectônica de teclas da Bacia Potiguar. In: CONGR. BRAS. GEOL., 34, Goiânia, 1986. Anais... Goiânia, SBG, v.3, p. 1145-1159.

FRANCOLIN, J.B.L. \& SZATMARI, P. 1987. Mecanismo de rifteamento na porção oriental da margem norte brasileira. Rev. Bras. Geoc., 17(2):195-207. 
GAVA, A.; NASCIMENTO; D.A, do; VIDAL, J.L.B.; CHIGNONE, J.I.; OLIVEIRA, E.P. de; SANTIAGO FILHO, A.L.; TEIXEIRA, W.; STANFORD, W.J.P.; RIBEIRO, A.G.; RIBEIRO, J.H.M. 1983. Geologia. In: PROJETO RADAMBRASIL. Folha SC.24/25 Aracaju/Recife: geologia, geomorfologia, pedologia, vegetação e uso potencial da terra. Rio de Janeiro, MME/Secretaria Geral. p.27-376 (Lev. Rec. Nat. 30)

GOMES, J.R.C.; GATTO, C.M.P.P.; SOUZA, G.M.C. de; LUZ, D.S da; PIRES, J.L.; TEIXEIRA, W.; FRANCA, F.A.B, de; CABRAL, E.M.A.; MENOR, E.A.; MONTEIRO, N.; BARROS, M.J.G.; RIBEIRO, E.G.; LIMA, E.A. de; FONSECA, R.A. da. 1981. Geologia. In: PROJETO RADAMBRASIL. Folhas SB.24/25 Jaguaribe e Natal: geologia, geomorfologia, pedologia, vegetaçâo e uso potencial da terra. Rio de Janeiro, MME/Secretaria Geral. p.27-300 (Lev. Rec. Nat. 23)

GORINI, M.A. \& BRYAN, G.M. 1976. The tectonic fabric of the Equatorial Atlantic and adjoining continental margins: Gulf of Guinea to Northeastern Brazil. An. Acad. bras. Ciênc., 48(supl.):101-119.

HORN, P.; MÜLLER-SOHNIUS, D.; SCHULT, A. 1988. Potassiumargon ages on a mesozoic tholeiitic dyke swarm in Rio Grande do Norte, Brazil. Rev. Bras. Geoc., 18(1):50-53.

INSTITUTO DE PESOUISAS TECNOLÓGICAS DO ESTADO DE SĀO PAULO (IPT). 1988. A Reativaçāo Wealdeniana no Brasil: uma revisāo sobre o Nordeste Oriental. SåoPaulo,IPT. (Rel. 26566)

KEGEL, W. 1957. Contribuição ao estudo da Bacia Costeira do Rio Grande do Norte. Rio de Janeiro, 52 p. (Bol. DMG 170)

KLEIN, V.C. \& VALENCA, J.G. 1984. Estruturas almofadadas em derrame ankaramítico na Bacia de São José de Itaborá, Rio de Janeiro. In: CONGR. BRAS. GEOL., 33, Rio de Janeiro, 1984. Anais... Rio de Janeiro, SBG. v. 9, p. 4335-4345.

KOWSMANN, R.O. \& COSTA, M.P.A. 1976. Estratigrafia sísmica do Platô de Pernambuco. Rev. Bras. Geoc., 6(2):95-101.

LEGRAND, J.M. \& FIGUEIREDO FILHO, O.A. 1979. Reavaliaçāo dos dados isotópicos da Província Magmática do Cabo. In: SIMP. GEOL. NORDESTE, 9, Natal, 1979. Atas... Natal, SBG/NNE. p.111-117.

LIMA, E.A.M. \& LEITE, J.F. 1978. Projeto estudo global dos recursos minerais da bacia sedimentar do Parnaiba. Recife, DNPM/CPRM. $16 \mathrm{v}$. (integração geológica e metalogenética)

LONG, L.E.; SIALL, A.N.; NEKVASIL, H.; BORBA, G.S. 1986. Origin of granite of Cabo de Santo Agostinho, Northeast Brazil. Contrib. Miner. Petrol., 92:311-315.

MAYER, E. 1974. Estratigrafia preliminar na plataforma continental da Bacia Potiguar. Rio Grande do Norte. s. 1. Petrobrás (inédito).

MIRANDA, F.P.; LIU, C.C.; RODRIGUES, J.E. 1986. Análise estrutural e tectônica do Pré-Cambriano adjacente às Bacias Barreirinhas e do Ceará, através de dados de sensores remotos. Rio de Janeiro, Petrobrás/Cenpes/MCT/INPE. 99 p. (Rel. Téc. Cenpes 736)

MIZUSAKI, A.M.P. 1988. A Formaçāo Macau na porçāo submersa da Bacia Potiguar (RN). Rio de Janeiro, Bol. Geoc. Petrobrás. (submetido)

NASCIMENTO, D.A. do; GAVA, A.; PIRES, J.L.; TEIXEIRA, W. 1981. Geologia. In: PROJETO RADAMBRASIL. Folha SA.24 Fortaleza: geologia, geomorfologia, pedologia, vegetação e uso potencial da terra. Rio de Janeiro, MME/SG. p.9-212 (Lev. Rec. Nat. 21).

PRIEN, H.N.A.; BOELRIJK, N.A.I.M.; VERSCHURE, R.H.; HEBEDA, E.H.; VERDUMEM, E.A. Th.; BON, E.H. 1978. $\mathrm{K}-\mathrm{Ar}$ dating of a basaltic layer in the sedimentary Lavras Basin, northeastern Brazil.Rev. Bras. Geoc., 8(4):262-269.

RAO, A.B. \& SIAL, A.N. 1972. Observations on alkaline plugs near Fortaleza city, Ceará state, Brazil. In: INTERN. GEOL. CONGR., 24, Montreal, 1972. Proceed... Montreal, IUGS. Sec. 14, p. $56-61$.

REZENDE, W.M. de 1964. Bacia do Maranhāo-estudos dos processos de intrusōes e extrusōes de magmas básicos. Rio de Janeiro, Petrobrás/Depex. 23 p.

RICCOMINI, C.; MELO, M.S. de; CARNEIRO, C.D.R.; ALMEIDA, F.F.M. de; MIOTO, J.A.; HASUI, Y, 1983. Sobre a ocorrência de um derrame de ankaramito na Bacia de Volta Redonda (RJ) e sua importância na datação das bacias tafrogênicas continentais do sudeste brasileiro. In: SIMP. REG. GEOL., 4, São Paulo, 1983. Resumos... Sāo Paulo, SBG/NSP.p. 23-24.

RODRIGUES, F.B.H.; KLEIN, V.C.; CUNHA, F.L.S. 1982. Novas descobertas de rochas alcalinas na bacia de São Joăo, Itaborá, Rio de Janeiro. In: CONGR. BRAS. GEOL., 33, Rio de Janeiro, 1984. Anais... Rio de Janeiro, SBG. v. 9, p. 4335-4339.

RODRIGUES, M.F.B. 1976. Rochas basálticas do Rio Grande do Norte e Paraiba. São Paulo, 62 p. (Dissert. Mestrado, Inst. Geoc. USP.)

SANTOS, E.J. dos 1968. Contribuiçāo ao estudo da geologia da quadrícula de Açu. Recife, Sudene/Divisāo de Geologia, 91 p. (Sudene, Geol. Reg. 6)

SANTOS, E.J. dos \& BRITO-NEVES, B.B. de. 1984. Província Borborema. in: ALMEIDA, F.F.M. de \& HASUI. Y. coords. $O$ Pré-Cambriano do Brasil. Sẩo Paulo, Blücher. p. 123-186.

SCHOBBENHAUS, C.; CAMPOS, D.A.; DERZE, G.R.; ASMUS, H.E. (coord.). 1981. Mapa Geológico do Brasil e da área oceânica adjacente. incluindo depósitos minerais; escala 1:2.500.00. Brasília, DNPM/MME.

SIAL, A.N. 1974. Petrology and tectonic significance of the post-paleozoic basaltic rocks of northeast Brazil. . (Ph.D. Thesis University of California)

SIAL, A.N. 1975. Petrologia e química mineral dos basaltos mesozóicos de Porto Franco e Grajaú, Maranhāo. In: SIMP. GEOL. NORDESTE, 7, Fortaleza, 1975. Atas... Fortaleza, SBG/NNE. p. 223-241.

SIAL, A.N. 1976a. The post-paleozoic volcanism of northeast Brazil and its tectonic significance. An. Acad. bras. Ciênc. 48(supl.):299-311.

SIAL, A.N. 1976b. The Rio Grande do Norte alcali-olivine-basalt association, Northeast Brazil. Rev. Bras. Geoc., 6(1):1-14.

SIAL, A.N.; LONG, L.E.; PESSOA, D.A.R.; KAWASHITA, K. 1981. Potassium-argon ages and strontium isotope geochemistry of Mesozoic and Tertiary basaltic rocks, northeastern Brazil. An Acad. bras. Ciênc., 53:112-115.

SIAL, A.N. OLIVEIRA, E.P. CHOUDHURI, A. 1987. Mafic dyke swarms of Brasil. In: HALLS, H.C. \& PAHRIG, W.F. eds. Mafic dyke swarms. p.467-481. (Geol. Asoc. Canada Spec. Paper 34)

SIBUET, J.C. \& MASCLE, J.R. 1978. Plate kinematic implications of Atlantic Equatorial Fracture zones trends. J. Geophys. Res., 83(B7):3401-3421.

SOUZA, S.M. de. 1982. Atualizaç̃o da litoestratigrafia da Bacia Potiguar. In: CONGR. BRAS. GEOL., 32, Salvador, 1982. Anais... Salvador, SBG. v. 5, p. 2392-2406.

SZATMARI, P.; FRANCOLIN, J.B.L.; ZANOTTO, O; WOLFF, S. 1987. Evolução tectônica da margem equatorial brasileira. Rev. Bras. Geoc., 17(2):180-188.

SYKES, L.R. 1978. Intraplate seismicity, reactivation of preexisting zones of weakness, alkaline magmatism, and other tectonism postdating continental fragmentation. Rev. Geophys. Spac. Phys., 16(4):621-688.

THOMAZ FILHO, A. 1983. Datação radiométrica de rochas tgneas básicas da bacia do Ceará. Rio de Janeiro, Petrobrás/Cenpes. (Rel. int. Cenpes 673-4462)

VANDOROS, P.; CORDANI, U.G.; MATZKU, J.J. 1966. Idades absolutas das rochas ígneas da região de Cabo, Pernambuco. In: CONGR. BRAS. GEOL., 20, Vitória, 1966. Res. Com.... Vitória, SBG. p. 64-66. (Publ. Esp.)

VANDOROS, P. \& OLIVEIRA, M.A.F. 1968. Sobre o fonбlito de Mecejana, Ceará. An. Acad, bras. Ciênc., 40(2):203-206.

ZALÁN, P.V. \& WARME, J.E. 1985. Tectonics and sedimentation of the Piaut-Camocim Sub-basin, Ceara Basin. Offshore Northeastern Brazil. Rio de Janeiro, Petrobrás/Cenpes/Dintep. 71p. (Série Ciênc. Tec. Petróleo 17)

ZALÁN, P.V.; NELSON, E.P.; WARME, J.E.; DAVIS, T.L. 1985. The Piaú Basin: rifting and wrenching in an equatorial atlantic transform basin. The Soc. of Econ. Paleont. and Mineralogists. p. 177-192 (Spec. Public. 37)

MANUSCRITO 564

Recebido em 30 de junho de 1988 Revisāo aceita em 13 de setembro de 1988 